\title{
Additional Nuclear Criticality \\ Safety Calculations for \\ Small-Diameter Containers
}

January 1996

By

M. J. Hone

Lockheed Martin Utility Services, Inc

PORTSMOUTH GASEOUS DIFFUSION PLANT

P.O. Box 628 Piketon, Ohio 45661

Under Contract USEC-96-C-0001

to the

\section{U.S. ENRICHMENT CORPORATION}

\section{MASTER}

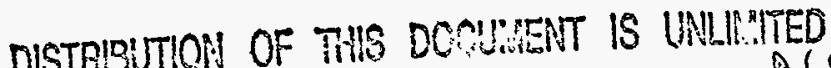




\section{NOTICE}

This report was prepared as an account of work sponsored by an agency of the United States Government. Neither the United States Government nor any agency thereof, nor any of their employees, makes any warranty, express or implied, or assumes any legal liability or responsibility for the accuracy, completeness, or usefulness of any information, apparatus, product, or process disclosed, or represents that its use would not infringe privately owned rights. Reference herein to any specific commercial product, process, or service by trade name, trademark, manufacturer, or otherwise, does not necessarily constitute or imply its endorsement, recommendation, or favoring by the United States Government or any agency thereof. The views and opinions of authors expressed herein do not necessarily state or reflect those of the United States Government or any agency thereof.

This report has been reproduced directly from the best available copy.

Available to DOE and DOE contractors from the Office of Scientific and Technical Information, P. O. Box 62, Oak Ridge, TN 37831; prices available from (615) 576-8401, FTS 626-8401.

Available to the public from the National Technical Information Service, U.S. Department of Commerce, 5285 Port Royal Rd., Springfield, VA 22161. 


\section{DISTRIBUTION}

\section{LOCKHEED MARTIN UTILITY SERVICES, INC.}

\section{PORTSMOUTH}
D. D'Aquila
J. Rapp
R. Dunham
B. Rumble (4)
J. Harris
J. Smith
M. Hone
Technical Review (3)
R. Oxenham
Central Files (2)
R. Lemming
X-710 Technical Library (2)
M. Plaster
R. Tayloe
B. Lee (4)
J. Henkel
D. Smallwood
M. LeTellier
D. Smith
D. Lindenschmidt
V. Pasupathi

OAK RIDGE
C. Jordan
H. Dyer
K. Shaffer
C. Haught
H. Dyer
K. Shaffer
S. Love 
Table of Contents

List of Figures $\ldots \ldots \ldots \ldots \ldots \ldots \ldots \ldots \ldots \ldots \ldots \ldots \ldots \ldots \ldots \ldots$ iii

List of Tables $\ldots \ldots \ldots \ldots \ldots \ldots \ldots \ldots \ldots \ldots \ldots \ldots$ iv

1.0 Introduction $\ldots \ldots \ldots \ldots \ldots \ldots \ldots \ldots \ldots \ldots \ldots \ldots \ldots \ldots \ldots \ldots \ldots$

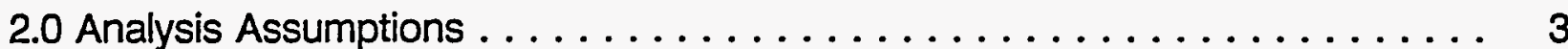

2.1 Models ............................ 3

2.1.1 Computer Models Used . . . . . . . . . . . . . 3

2.1.2 Model Approximations . . . . . . . . . . . . . . 3

2.2 Geometry Models . . . . . . . . . . . . . . . . . . . . 4

2.2.1 Definition of Standard Room (SR) . . . . . . . . . 4

2.2.2 Single Container Full Reflection (SFR) . . . . . . . . . 4

2.2.3 Single Container in a Concrete Corner (SCC) . . . . . . . . 5

2.2.4 Single Container with More Reactive Contents (SMRC) . . . . . 5

2.2.5 Two Containers Adjacent to a Concrete Wall (TACW) ...... . 5

2.2.6 Two Containers Separated from a Concrete Wall (TSCW) ... 6

2.2.7 Arrays in a Concrete Enclosure (ACE) . . . . . . . . . 6

2.2 .8 Interstitial Moderation (Al) . . . . . . . . . . . . . 7

2.2.9 Array with an Overloaded Single Position (AOSP) . . . . . . 7

2.3 Uranium Compounds Analyzed . . . . . . . . . . . . . . . 12

3.0 Determination of Number Densities $\ldots \ldots \ldots \ldots \ldots \ldots \ldots \ldots$

4.0 Results . . . . . . . . . . . . . . . . 21

4.1 4.32-inch-Diameter by 50 -inch-tall Polyethylene Bottle . . . . . . 21

4.2 5.0-inch-Diameter by 24 -inch-Tall Polyethylene Container . . . . . . . . 23

4.3 5.25-inch-Diameter by 24 -inch-Tall Steel Container (F-can) . . . . . . . 28

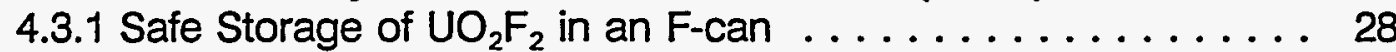

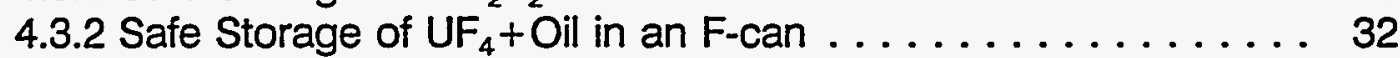

4.4 5.25-inch-Diameter by 15 -inch-tall Steel Container (Z-can) . . . . . . . 37

4.5 5.0-inch-Diameter by 9-inch-tall Polybottle ("CO-4" Polybottle) . . . . . . 39

4.6 Array Position Relative to Concrete Wall . . . . . . . . . . . . . 39

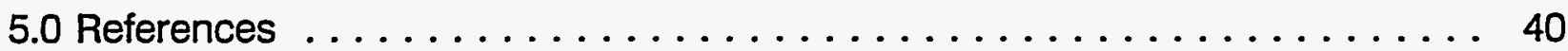




\section{Table of Contents (Continued)}

6.0 Appendix . . . . . . . . . . . . . . . . . . . . . 41

6.1 Sample Input deck for SFR geometry (deck x977c) . . . . . . . . 41

6.2 Sample Input deck for SCC geometry (deck y977c) . . . . . . . . . 42

6.3 Sample Input deck for TACW geometry (deck z977c) . . . . . . . 43

6.4 Sample Input deck for ACE geometry (deck ac977c) . . . . . . . . . 44

6.5 Sample Input deck for ACE-F geometry (deck af977c) . . . . . . . 45

6.6 Sample Input deck for AOSP geometry (deck a0977c) . . . . . . . 46

6.7 Sample Input deck for SFR-SHORT geometry (deck xx977) . . . . . . 47

6.8 Sample Input deck for TACW-SHORT geometry (deck zz977) . . . . . 48

6.9 Sample Input deck for SMRC geometry (deck smrc) . . . . . . . . . 49 


\section{List of Figures}

Figure 2.2.3-1

Figure 2.2.5-1

Figure 2.2.6-1

Figure 2.2.7-1

Figure 4.1-1

Figure 4.2-1

Figure 4.2-2

Figure 4.2-3

Figure 4.3.1-1

Figure 4.3.1-2

Figure 4.3.2-1

Figure 4.3.2-2

Figure 4.3.2-3

Figure 4.3.2-4

Figure 4.4-1
Single Container in a Concrete Corner with Water Reflector Simulating a Person .................. 8 Two Containers Next to a Concrete Wall with Water Reflector Simulating a Person .................... 9 Two Containers 1-foot from a Wall with Water Reflector Simulating a Person ................. 10 Standard Array Configuration with Concrete Reflector . . . . . 11 Two 4.32" ID $\times$ 50" Tall Cylinders of $\mathrm{UF}_{4}$ and Oil Next to a Wall ........................... 22

Two 5.0" ID x 24" Tall Cylinders of $\mathrm{UO}_{2} \mathrm{~F}_{2}$ and Water Next to a Wall .......................... 25 Single Fully Reflected $5.00 "$ ID x 24 " Tall Cylinder of $80 \%$ Enriched $\mathrm{UF}_{4}$ and Oil . . . . . . . . . . . . . . 26 Contingency and Array Cases for 5.0" ID x 24" Tall Cylinders of $80 \%$ Enriched $U F_{4}$ and Oil . . . . . . . . . . . . 27 Single Fully Reflected $5.25^{\prime \prime}$ ID $\times 24^{\prime \prime}$ Tall Cylinder of $97.7 \%$ Enriched $\mathrm{UO}_{2} \mathrm{~F}_{2}+\mathrm{H}_{2} \mathrm{O} \ldots \ldots \ldots \ldots \ldots \ldots \ldots \ldots$ Contingency and Array Cases for 5.25" ID X 24" Tall Cylinders of $97.7 \%$ Enriched $\mathrm{UO}_{2} \mathrm{~F}_{2}+\mathrm{H}_{2} \mathrm{O} \ldots \ldots \ldots \ldots \ldots \ldots$ Single Fully Reflected $5.25^{\prime \prime}$ ID $\times 24^{\prime \prime}$ Tall Cylinder of $60 \%$ Enriched $\mathrm{UF}_{4}+$ Oil . . . . . . . . . . . . . . . . 33 Single Fully Reflected $5.25^{\prime \prime}$ ID $\times 24^{\prime \prime}$ Tall Cylinder of $70 \%$ thru 97.7\% Enriched $\mathrm{UF}_{4}+$ Oil . . . . . . . . . . . . . . 34 Safe Mass Limits Versus Enrichment for $\mathrm{UF}_{4}+$ Oil in a 5.25" ID x 24" Tall Steel Container . . . . . . . . . . . . . . . 35 Contingency and Array Cases for 5.25" ID X 24" Tall Cylinders of $97.7 \%$ Enriched $\mathrm{UF}_{4}+$ Oil . . . . . . . . . . . . 36 Two 5.25" ID $\times 15^{\prime \prime}$ Tall Cylinders of $\mathrm{U}_{3} \mathrm{O}_{8}+\mathrm{H}_{2} \mathrm{O}$ Next to a Wall

\section{8}

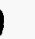
0 11 


\section{List of Tables}

Table 1.0.1

Table 3.0-1

Table 3.0-2

Table 3.0-3

Table 3.0-4

Table 3.0-5

Table 3.0-6
Small Diameter Uranium Bearing Containers .......... 2 Number Densities (atoms/bn-cm) for $\mathrm{UF}_{4}+$ Oil with $100 \%$ Enriched Uranium . . . . . . . . . . . . . . . . 15 Number Densities (atoms/bn-cm) for $\mathrm{UF}_{4}+$ Oil with $97.7 \%$ Enriched Uranium . . . . . . . . . . . . . . 16 Number Densities (atoms/bn-cm) for $\mathrm{UF}_{4}+$ Oil with $90.0 \%$ Enriched Uranium . . . . . . . . . . . . . . . 17 Number Densities (atoms/bn-cm) for $\mathrm{UF}_{4}+$ Oil with $80.0 \%$ Enriched Uranium . . . . . . . . . . . . . . . 18 Number Densities (atoms/bn-cm) for $\mathrm{UF}_{4}+$ Oil with $70.0 \%$ Enriched Uranium ..................... 19 Number Densities (atoms/bn-cm) for $\mathrm{UF}_{4}+$ Oil with $60 \%$ Enriched Uranium 


\section{Additional Nuclear Criticality Safety Analysis Calculations for Small-Diameter Containers}

\subsection{Introduction}

This report documents additional criticality safety analysis calculations for small diameter containers, which were originally documented in Reference 1. The results in Reference 1 indicated that some of the small diameter containers did not meet the criteria established for criticality safety at the Portsmouth facility $\left(\mathrm{K}_{\mathrm{eff}}+2 \sigma<.95\right)$ when modeled under various contingency assumptions of reflection and moderation. The calculations performed in this report reexamine those cases which did not meet the criticality safety criteria. In some cases, unnecessary conservatism is removed, and in other cases mass or assay limits are established for use with the respective containers.

The five basic containers considered in this report are:

1. 4.32-inch-diameter by 50 -inch-high polyethylene bottle

2. 5.0 -inch-diameter by 24 -inch-high polyethylene bottle

3. 5.25-inch-diameter by 24-inch-high steel can ("F-can")

4. $\quad 5.25$-inch-diameter by 15 -inch-high steel can ("Z-can")

5. $\quad 5.0$-inch-diameter by 9-inch-high polybottle ("CO-4")

The above five containers bound all container geometries listed in Table 1.0-1.

Most of the additional calculations are performed with $\mathrm{UF}_{4}+$ Oil in the container, as this was the most reactive material identified in Reference 1. However, some of the calculations consider $\mathrm{UO}_{2} \mathrm{~F}_{2}+\mathrm{H}_{2} \mathrm{O}$ or $\mathrm{U}_{3} \mathrm{O}_{8}+\mathrm{H}_{2} \mathrm{O}$ as well. Each container is evaluated in single and multi-unit geometry under normal and credible abnormal conditions. The KENO study results from this report, in conjunction with results from Reference 1, may be used for evaluating general use of these containers in the plant. 
Table 1.0.1

\section{Small Diameter Uranium Bearing Containers}

\begin{tabular}{|c|c|c|c|c|}
\hline Container Type & $\begin{array}{l}\text { Reference } \\
\text { Drawing \# }\end{array}$ & $\begin{array}{c}\text { Inner Diameter } \\
\text { (inches) }\end{array}$ & $\begin{array}{l}\text { Height } \\
\text { (inches) }\end{array}$ & $\begin{array}{c}\text { Wall Thickness } \\
\text { (Inches) }\end{array}$ \\
\hline $\begin{array}{l}\text { "744G" Polyethylene } \\
\text { Bottle }\end{array}$ & DX-761-2340-M, Rov 0 & $\begin{array}{c}4.25 \\
(+/-.07-i n)\end{array}$ & 50.373 & $\begin{array}{c}0.125 \\
(+.07,-.000)\end{array}$ \\
\hline $\begin{array}{l}\text { "24-in Polybottle" } \\
\text { Polyethylene Bottle }\end{array}$ & BX-761-M373, Rev 0 & 5.0 & 24.0 & (Min. 0.1875) \\
\hline $\begin{array}{l}\text { "GP Container" } \\
\text { Polyethylene Bottle }\end{array}$ & DX-761-2586-M, Rev 0 & 5.0 & 23.75 & 0.13 \\
\hline $\begin{array}{l}\text { "OG Container" } \\
\text { Polyethylene Bottle } \\
\end{array}$ & $\begin{array}{c}\text { Not Available } \\
\text { (Conceptual container) }\end{array}$ & 4.25 & 24.0 & Not Available \\
\hline $\begin{array}{l}\text { "CO-4 Polybottle" } \\
\text { Polyethylene Bottle }\end{array}$ & Not Available & 5.0 & 9.0 & Not Available \\
\hline $\begin{array}{l}\text { "F-Can" Tin Plated } \\
\text { Steel Container }\end{array}$ & DX-761-M-981 & 5.25 & 24.0 & Min. 0.015 \\
\hline $\begin{array}{l}\text { "Z-Can" Tin Plated } \\
\text { Steel Container }\end{array}$ & $D X-761-2331-M$ & 5.25 & 15.0 & Min. 0.015 \\
\hline
\end{tabular}


POEF-SH-43

\subsection{Analysis Assumptions}

\subsection{Models}

\subsubsection{Computer Models Used}

All calculations were performed on the Battelle Process Safety and Risk Management IBM RS/6000 workstation implementation of SCALE-4.2. The CSAS25 calculational sequence was used in conjunction with the 27 Energy Group ENDF/B-IV cross section library. The validation performed on this software/hardware combination and its area of applicability are discussed in References 2 and 3. Configuration control of this software/hardware combination is documented in Reference 4.

The CSAS25 modules consists of BONAMI, NITAWL, and KENO Va. BONAMI and NITAWL adjust the cross section data for the problem at hand, while KENO Va is used to determine the K-effective of each problem. Reference 1 contains validation arguments for using the above code system to model the small diameter containers in conjunction with the $\mathrm{UO}_{2} \mathrm{~F}_{2}+\mathrm{H}_{2} \mathrm{O}, \mathrm{U}_{3} \mathrm{O}_{8}+\mathrm{H}_{2} \mathrm{O}$, and $\mathrm{UF}_{4}+$ Oil materials. The same arguments apply to the calculations performed in this analysis. The only significant difference is that intermediate enrichments of between $60-90 \%$ are modeled in this analysis, whereas the Reference 1 analysis considered only $100 \%$ and $10 \%$ enriched cases. The intermediate enriched cases are bounded by the high $(>93 \%)$ and low $(<4.9 \%)$ enriched benchmark cases presented in the validation report. In addition, it has been confirmed that the average energy group causing fission for the intermediate enriched cases is consistent with the majority of the benchmark cases. Any systematic bias in K-effective, which is caused by inaccuracies in the $\mathrm{U}^{235}$ or $\mathrm{U}^{238}$ cross sections, would be expected to behave continuously and monotonically as a function of the $U^{235}$ enrichment of the material. In other words, the bias for mid-enriched cases should be somewhere between the bias for low and high-enriched cases of the same material and geometry. Based on the above arguments, it is concluded that the continued application of the $\mathrm{K}_{\text {eff }}+2 \sigma<.95$ criteria will ensure that mid-enriched cases will be subcritical (with a confidence level comparable to that of the high and low enriched cases).

\subsubsection{Model Approximations}

Steel containers are modeled as simple cylinders of the fissile material. There is no credit taken for the neutron absorption in the container itself, because the tolerances on the container dimensions are not well defined, and because of the possibility of container corrosion. Polyethylene containers are modeled as a fissile cylinder surrounded by the maximum thickness of POLY(H2O), since this material reflects neutrons. The only exception to this is in the fully reflected geometry (see Section 2.2.2), where modeling the polyethylene was shown in Reference 1 not to significantly effect the results. 


\subsection{Geometry Models}

The standard geometry models used for analyzing small containers at the Portsmouth Plant are described in References 1 and 5 . In some cases, unnecessary conservatism has been removed from the standard geometries. Each of the geometry models used in this analysis is described in the following sections and is assigned an acronym for identification purposes. Sample input files are contained in the appendix.

\subsubsection{Definition of Standard Room (SR)}

This model applies to all cases with the exception of the full water reflection case, which does not require the addition of any external reflector. The basic parameters defining a standard room are:

Floor: $\quad 24$ inch thick regular concrete floor

Ceiling: $\quad 12$ inch thick regular concrete ceiling (10 ft high)

Walls: $\quad 12$ inch thick concrete walls

In analyzing some of the containers, exceptions were taken to the standard room dimensions, with the intent that the use of the containers may be limited in rooms which are not bounded by the analyzed dimensions. Specific exceptions to the standard room dimensions are noted in the results summary for each container.

\subsubsection{Single Container Full Reflection (SFR)}

The SFR geometry simulates a single container of fissile material sitting on a concrete slab floor with SR dimensions (unless otherwise noted in the results), and surrounded by at least 12 " of close fitting full density water on all other sides.

A related geometry condition considered in this analysis is designated "SFRSHORT". SFR-SHORT is applicable only in the situation when mass limits are established. It is identical to the SFR geometry except that the container is assumed to contain two stratified layers of material. The bottom layer contains the mass limit of the fissile material at the optimum $\mathrm{H} / \mathrm{U}$ ratio, and the top layer contains a reflector of hydrogenous material (oil or water, depending on the material involved). The optimum $\mathrm{H} / \mathrm{U}$ ratio for a given material and its corresponding uranium density can be determined from the original SFR cases. Then given the uranium density and a prospective mass limit, the volume (and height) of the fissile material layer can be calculated. 
POEF-SH-43

\subsubsection{Single Container in a Concrete Corner (SCC)}

The SCC geometry simulates a single container placed in a corner, in contact with two concrete walls and the concrete floor. The walls and floor use SR dimensions unless otherwise noted in the results. The model also includes contact by a person handling the container. The person is modeled as $\sim 100 \mathrm{~kg}$ of water that is $\mathrm{L}$ shaped around the sides and top of the container, as shown in Figure 2.2.3-1. As a result, the container is entirely enveloped by either concrete or water.

\subsubsection{Single Container with More Reactive Contents (SMRC)}

In this geometry, an administrative control on either allowable material, allowable mass, or allowable assay is assumed to be violated, with the result that the most reactive material at the optimum $\mathrm{H} / \mathrm{U}$ is placed in a single container. The container is assumed to be placed on a concrete floor, and is assumed to have a $1^{11}$ close fitting water reflector, to simulate a nominal amount of reflection. The misloading of the container represents a single unlikely contingency. Under contingency conditions, full reflection is not considered.

\subsubsection{Two Containers Adjacent to a Concrete Wall (TACW)}

This model simulates the unlikely contingency of having two containers touching in a position adjacent to a concrete wall and floor, and reflected by a person. The person is modeled as $\sim 100 \mathrm{~kg}$ block of pure water, $18^{\prime \prime}$ wide by $7^{\prime \prime}$ deep by $4^{\prime}$ high. The concrete walls and floor use SR dimensions unless otherwise noted in the results. The person is assumed to be in the act of setting down or picking up both containers with hands which are modeled as 1-inch-thick slabs. The TACW geometry is shown in Figure 2.2.5-1. There are three changes made to the assumptions behind the TACW geometry from Reference 1, in order to remove unnecessary conservatism. These changes deal with the amount of reflection and interaction. The changes are discussed and justified below.

1) The hands of the person are assumed to be $6^{\prime \prime}$ in the $Z$ direction, and are assumed to be located adjacent either to the top $6^{\prime \prime}$ or to the center of both containers. In Reference 1, the hands were assumed to be the same height as the

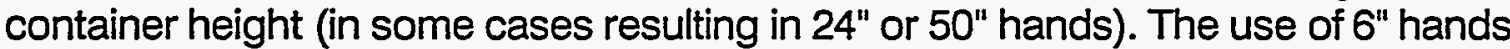
is a more realistic representation of human hands. The assumption that the hands are at the top of the containers (as opposed to centered) is also more realistic in the case of some containers ( $F$ and Z-cans), which have handles near the top. For all other containers, the hands are assumed to be centered on the container. It should be noted that the presence of two hands in the model is still conservative, since there would ordinarily be an administrative restriction placed on moving more than one container at a time. 
2) The bulk of the $100 \mathrm{Kg}$ person is assumed to be at least $2^{\prime \prime}$ away from the containers. In Reference 1 , the $100 \mathrm{Kg}$ person was assumed to be immediately adjacent to both containers (ie 0 " separation). The revised assumption is based on the observation that a person picking up or setting down a container would a) want to see what he is doing, and b) want to avoid contacting the concrete wall while bending over. Experiments were performed with an F-can next to a wall, in order to determine the most likely relative position of a person picking up the can. It was determined that the most comfortable position results in the legs of the person being at least $4^{\prime \prime}$ from the container, hence the $2^{\prime \prime}$ assumption is still somewhat conservative. Overall, the reflection occurring from the $100 \mathrm{Kg}$ water block has been reduced relative to Reference 1, but it is still more than would reasonably be expected to occur from a person moving the containers.

3) The assumption that the two containers are immediately adjacent to each other and to the concrete wall is relaxed in the case of GP Poly bottle containers. The lid on 5" GP poly bottles is at least 6.63" in outer diameter, and this effectively limits how close the GP bottles can be to the wall and to each other.

A related geometry condition considered in this analysis is designated "TACWSHORT". This geometry is analogous to the SFR-SHORT geometry discussed earlier, and is only applicable in the case when mass limits are established. For TACW-SHORT, both containers are assumed to contain the same stratified layers as the SFR-SHORT container. All other TACW geometry parameters remain the same as discussed above.

\subsubsection{Two Containers Separated from a Concrete Wall (TSCW)}

This geometry was utilized in Reference 1 to simulate a situation similar to the TACW geometry, except that the reflection from the concrete wall was effectively removed by placing the cans one foot from the wall, instead of next to the wall. TSCW cases are only executed in this analysis when TACW cases can not be shown to meet the safety limit, because the TACW geometry (with more reflection) always bounds the TSCW geometry. The only change to this geometry from the Reference 1 geometry is that the hands are modeled as $6^{\prime \prime}$ in the $Z$ direction, instead of being the same height as the container. The $100 \mathrm{Kg}$ person is assumed to be in direct contact with the cans in this geometry, as shown in Figure 2.2.6-1.

\subsubsection{Arrays in a Concrete Enclosure (ACE)}

This geometry models four double rows of containers located in a concrete room, as shown in Figure 2.2.7-1. SR dimensions are used, unless otherwise noted in the results. A double row consists of 2 rows of containers separated by 23 inches center-to-center. The rows are 40 units long, and each double row is separated by 6-foot aisles. The array is a minimum of 2 feet from the concrete walls. 


\subsubsection{Interstitial Moderation (Al)}

In Reference 1, cases were performed to quantify the effect of adding interstitial moderation to the spaces surrounding the containers in an ACE geometry. Cases were executed for several different containers, assuming from 0.0 to 0.1 volume fractions of water in these spaces. The results in all Reference 1 cases showed that the reactivity of the array was higher with no water than with up to 0.1 fraction of water present. There were a few exceptions where small amounts of water resulted in slightly higher reactivity, but these cases were probably the result of the statistical nature of the KENO-Va results. The reason the reactivity was generally higher with no water, is that having small amounts of water in the six foot aisles effectively eliminates neutronic interaction between the double rows, and this effect is initially larger than the increase in moderation. A fully flooded ACE array would increase to the same K-effective as the SFR geometry, because the 23" center to center spacing is large enough that each container would be neutronically isolated from its neighbors in a fully flooded condition. Fully flooded ACE array calculations (designated ACE-F) were performed for the F-cans and CO-4 Poly bottles to demonstrate this. As a result of these observations, there were no other Al cases executed in this analysis.

\subsubsection{Array with an Overloaded Single Position (AOSP)}

This geometry is nearly the same as the ACE geometry, except that one of the positions in the array is loaded with two adjacent containers and $100 \mathrm{~kg}$ of water, simulating a person. The array location chosen for the overload is a corner location, because of its proximity to the concrete walls. No flooding of the array is assumed in conjunction with the overload. 
Figure 2.2.3-1

Single Container in a Concrete Corner with Whater Reflector Simulating a Person
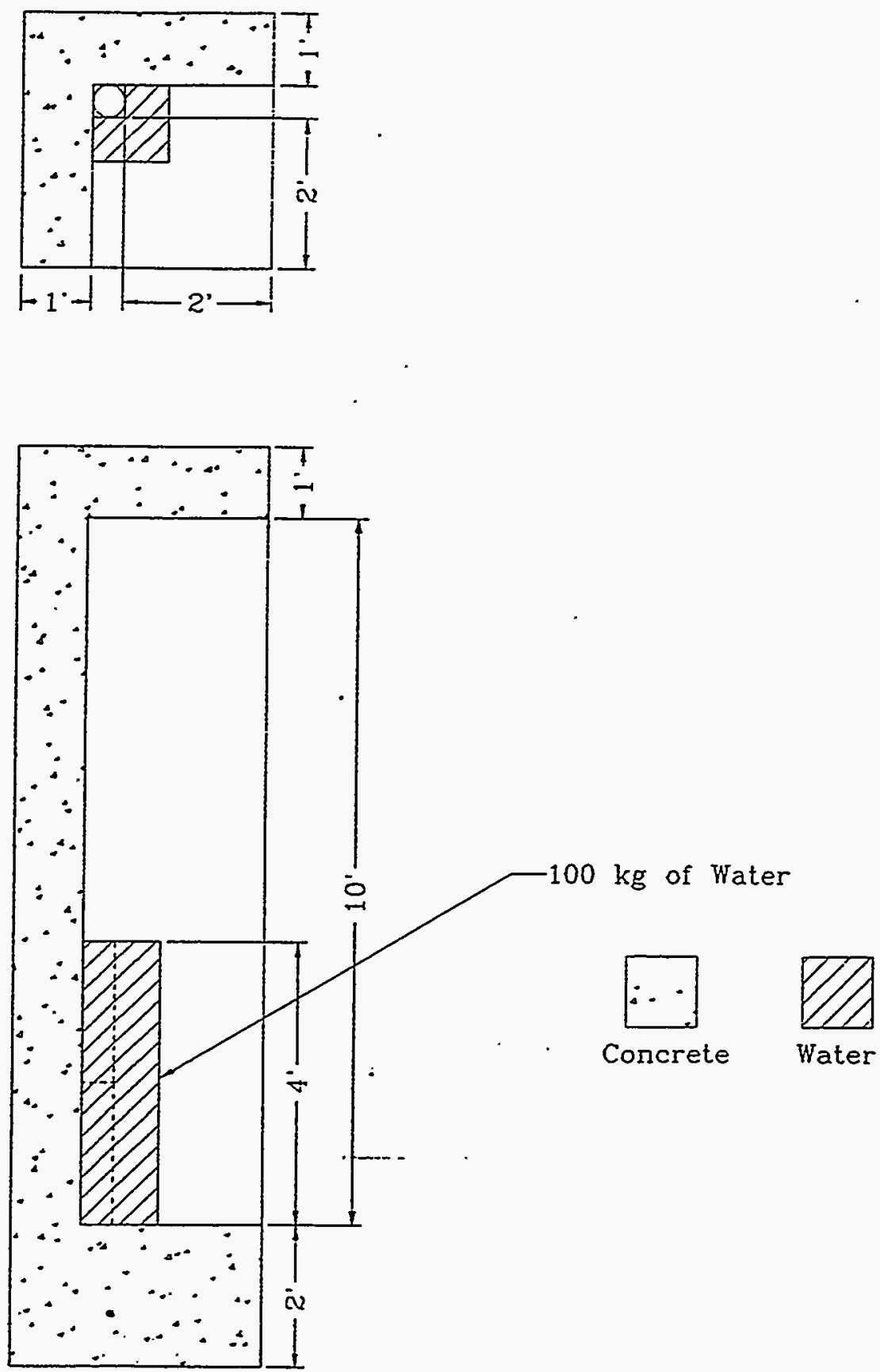
Figure 2.2.5-1

Two Containers Next to a Concrete Wall with Water Reflector Simulating a Person
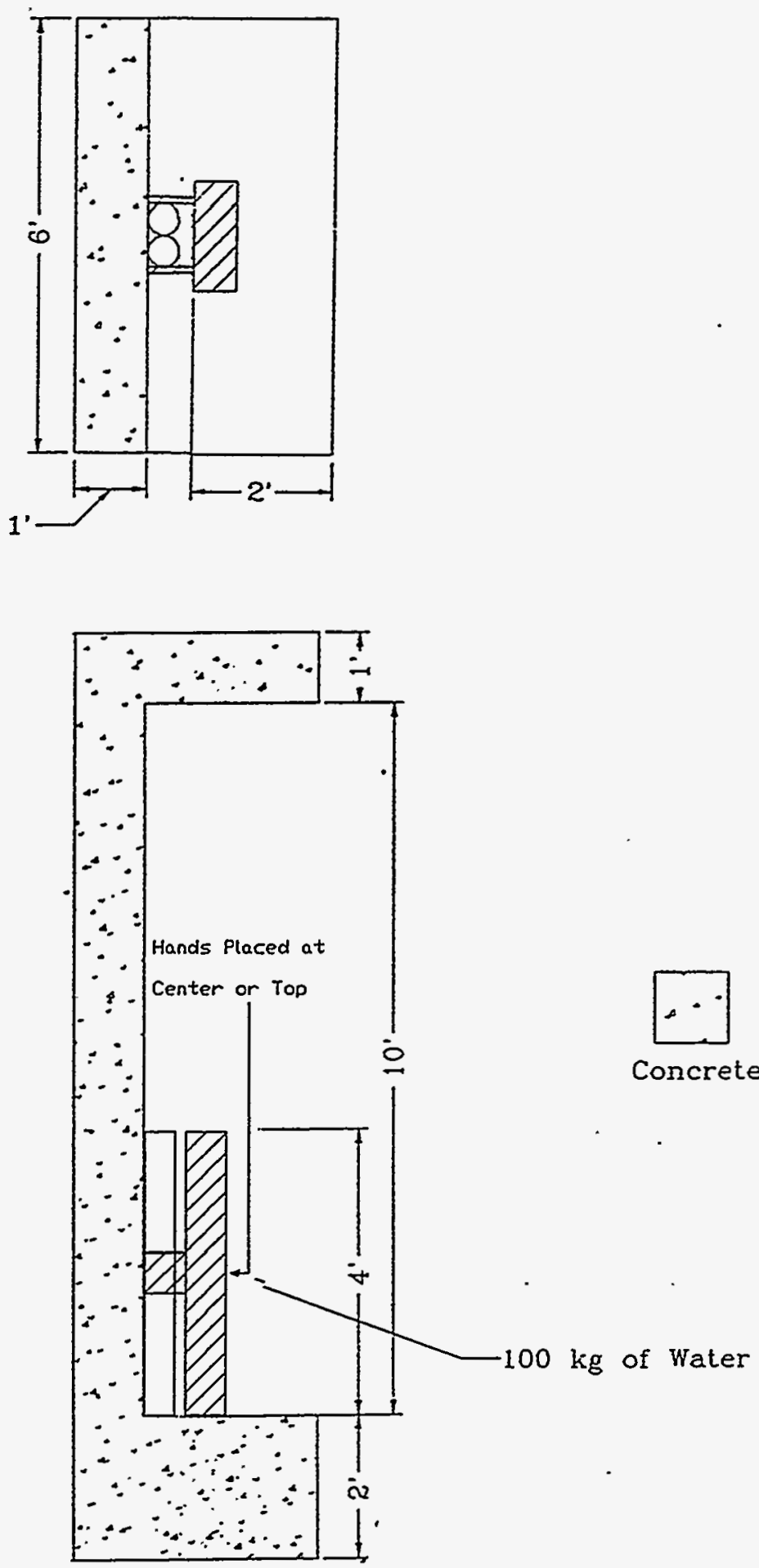
Figure 2.2.6-1

Two Containers 1-foot from a Wall with Water Reflector Simulating a Person
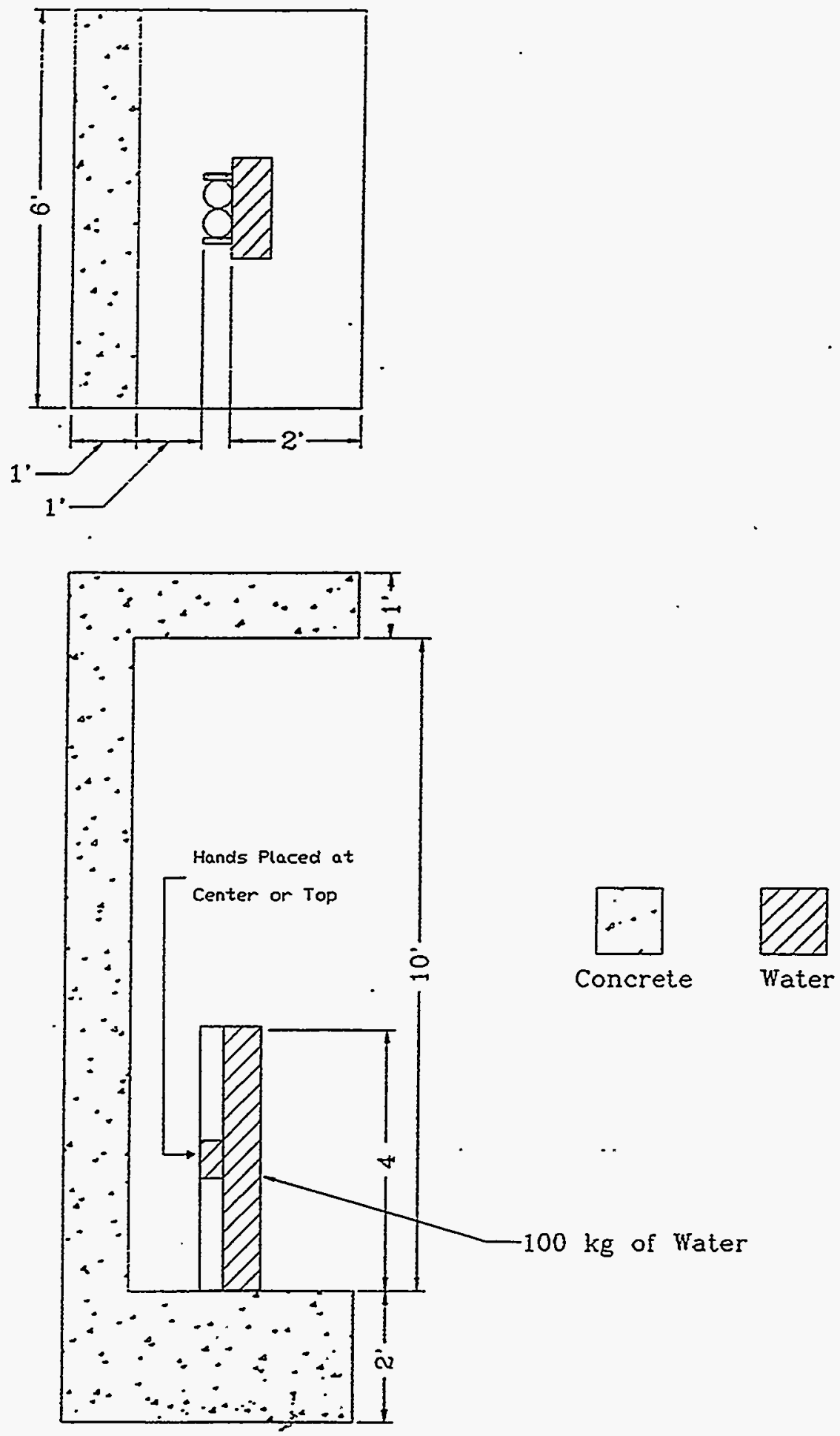
Figure 2.2.7-1

Standard Array Configuration wịth Concrete Reflector

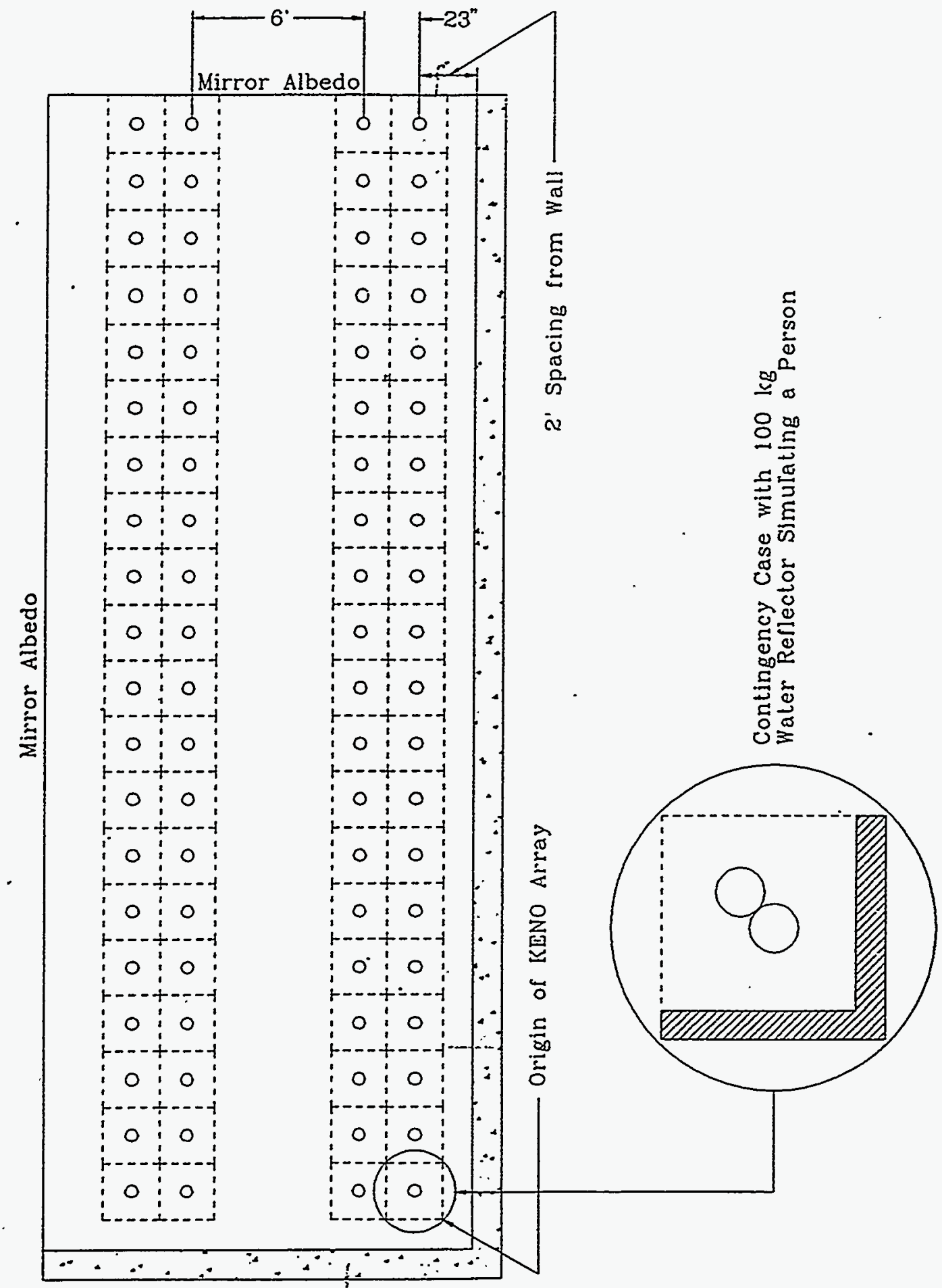




\subsection{Uranium Compounds Analyzed}

Uranium is present in many chemical forms at the Portsmouth Plant. The scope of this analysis is limited to the following three material types: $\mathrm{UO}_{2} \mathrm{~F}_{2}+\mathrm{H}_{2} \mathrm{O}, \mathrm{UF}_{4}+$ Oil, and $\mathrm{U}_{3} \mathrm{O}_{8}+\mathrm{H}_{2} \mathrm{O}$. In Reference 1, it was determined that the $\mathrm{UF}_{4}+$ Oil was the most reactive of the three, followed by $\mathrm{U}_{3} \mathrm{O}_{8}+\mathrm{H}_{2} \mathrm{O}$ and $\mathrm{UO}_{2} \mathrm{~F}_{2}+\mathrm{H}_{2} \mathrm{O}$ (which were virtually identical in reactivity at the optimum $\mathrm{H} / \mathrm{U}$ ratio).

The $\mathrm{UO}_{2} \mathrm{~F}_{2}+\mathrm{H}_{2} \mathrm{O}$ is of concern because of its high uranium solubility and because it is the most common of the above three materials. It results from the reaction of $U F_{6}$ and water during wet air inleakage. It is also more reactive than most other materials which are stored in small diameter containers, including discharged material from alumina and $\mathrm{NaF}$ chemical traps.

$\mathrm{UF}_{4}+$ Oil is the result of the reaction between $\mathrm{UF}_{6}$ and lubricating oil used in compressors or vacuum pumps. It is analyzed because it is more reactive than either of the other two compounds, and because it is sometimes stored in small diameter containers. Floor sweepings may also contain oil and uranium compounds, but these are considered bounded by the analysis of pure UF $_{4}+$ Oil. For the purposes of calculating number densities, the oil is assumed to be the simplistic molecule $\mathrm{CH}_{2}$. This assumption is consistent with the treatment of oil in Reference 1. In reality, the oil molecules are complex hydrocarbon chains with varying numbers of carbon and hydrogen atoms. However, the $\mathrm{H} / \mathrm{C}$ ratio on average is very close to $2: 1$, so approximating the oil as $\mathrm{CH}_{2}$ is a reasonable assumption.

$\mathrm{U}_{3} \mathrm{O}_{8}+\mathrm{H}_{2} \mathrm{O}$ is produced by Caiciner operations in the $\mathrm{X}-705$ building. It is slightly more reactive than $\mathrm{UO}_{2} \mathrm{~F}_{2}+\mathrm{H}_{2} \mathrm{O}$, but is considered only in the case of Z-cans and CO-4 poly bottles, which are used only for oxides. 


\subsection{Determination of Number Densities}

The number densities for the non-uranium compounds are generated internally by SCALE-4.2, by specifying compounds from the Standard Composition Library. The standard materials used are:

$\mathrm{H} 2 \mathrm{O} \quad$ Full density water: Cross Sections developed using 1/E weighting. REG-CONCRETE Regular concrete: $53.2 \mathrm{w} / \mathrm{o}$ Oxygen, $33.7 \mathrm{w} / \mathrm{o}$ Silicon, $4.4 \mathrm{w} / \mathrm{o}$ calcium, $3.4 \mathrm{w} / \mathrm{o}$ aluminum, $2.9 \mathrm{w} / \mathrm{o}$ sodium, $1.4 \mathrm{w} / \mathrm{o}$ iron, $1.0 \mathrm{w} / \mathrm{o}$ hydrogen.

POLY(H2O) Polyethylene: $\mathrm{C}_{2} \mathrm{H}_{4}$ at $.92 \mathrm{~g} / \mathrm{cc}$, uses hydrogen in water thermal kernel.

The number densities for the uranium compounds $\mathrm{UO}_{2} \mathrm{~F}_{2}+\mathrm{H}_{2} \mathrm{O}$ and $\mathrm{U}_{3} \mathrm{O}_{8}+\mathrm{H}_{2} \mathrm{O}$ are generated using the NUMDEN code, Version 1.1 (Reference 7). NUMDEN is a computer program capable of computing number densities and mixture weight percents for a variety of uranium bearing compounds, and producing the corresponding input cards for defining an arbitrary material KENO-Va.

NUMDEN uses the Barber relationship (Reference 7) for calculating the uranium densities of the $\mathrm{UO}_{2} \mathrm{~F}_{2}$ solutions considered in this report. As noted in Reference 1, the Barber relationship results in highly conservative uranium densities for $H / U$ values less than 4 . This resulted in discontinuities in the results presented in Reference 1 for K-effective versus $\mathrm{H} / \mathrm{U}$. Historically, US gaseous diffusion plants have used a maximum uranium density of $3.2 \mathrm{gU} / \mathrm{cc}$ for deposits removed from cascade equipment (Reference 8). Left undisturbed, $\mathrm{UO}_{2} \mathrm{~F}_{2}$ cascade deposits may approach theoretical density $(-4.9 \mathrm{gU} / \mathrm{cc})$. However, once disturbed by the process of mechanical recovery or exposure to ambient air, $\mathrm{UO}_{2} \mathrm{~F}_{2}$ behaves as a bulk powder, even if dried back to the anhydrous state. The use of $3.2 \mathrm{gU} / \mathrm{cc}$ as a maximum uranium density for the $\mathrm{UO}_{2} \mathrm{~F}_{2}$ deposits removed from the cascade conservatively bounds the actual bulk density of the material. This is implemented in the number density calculations by selecting the NUMDEN option to specify, rather than calculate, the uranium density for $\mathrm{UO}_{2} \mathrm{~F}_{2}$ cases with $\mathrm{H} / \mathrm{U}$ values less than 4.

The number densities for $\mathrm{UF}_{4}+$ Oil were computed using the volume-additive method, in conjunction with the following basic information:

$\begin{array}{ll}\mathrm{UF}_{4} \text { Density } & =6.7 \mathrm{~g} / \mathrm{cc} \text { (Ref 9) } \\ \text { Oil Density } & =.87 \mathrm{~g} / \mathrm{cc} \text { (Ref 6) (assumed to be } \mathrm{CH}_{2} \text { ) } \\ \mathrm{MW}_{\mathrm{F}} & =18.9984 \mathrm{~g} / \mathrm{mole} \text { (Ref 10) } \\ \mathrm{MW}_{\mathrm{U} 235} & =235.0439 \mathrm{~g} / \text { mole (Ref 10) } \\ \mathrm{MW}_{\mathrm{U} 238} & =238.0508 \mathrm{~g} / \mathrm{mole} \text { (Ref 10) } \\ \mathrm{MW}_{\mathrm{C}} & =12.011 \mathrm{~g} / \mathrm{mole} \text { (Ref 10) } \\ \mathrm{MW}_{\mathrm{H}} & =1.0079 \mathrm{~g} / \mathrm{mole} \text { (Ref 10) } \\ \mathrm{N}_{\mathrm{A}} & =6.02214 \mathrm{E}+23 \text { atoms } / \text { mole (Ref 11) }\end{array}$


The equations used to calculate the number densities of each element in the UF $\mathrm{F}_{4}+$ Oil compound are:

$$
\begin{aligned}
& N_{C}=\frac{\rho_{\text {oil }} * V_{F_{\text {ox }}} * N_{A} * 10^{-24}}{M W_{\text {oil }}} \\
& N_{H}=2 * N_{C} \\
& N_{U^{225}}=\frac{a / O_{U \text { Uas }} * \rho_{U F_{4}} * V_{F_{U U_{4}}} * N_{A} * 10^{-24}}{M W_{U F_{4}}} \\
& N_{U 200}=\frac{\left(1-a / O_{U^{20 s}}\right) * \rho_{U F_{4}} * V_{F_{U U_{A}}} * N_{A} * 10^{-24}}{M W_{U F_{4}}} \\
& N_{F}=4 *\left(N_{\text {Uass }}+N_{\text {Ursas }}\right)
\end{aligned}
$$

where:

$M W_{o i l}=M W_{c}+\left(2 * M W_{H}\right)$

$M W_{U F_{4}}=M W_{U}\left(4 * M W_{F}\right)$

and $V_{F}$ is an assumed volume fraction of Oil or $\mathrm{UF}_{4}$.

The results from the number density spreadsheet calculations are shown in Tables 3.0-1 thru 3.0-6. It should be noted that there are small differences between the number densities presented in this report and the analogous Reference 1 number densities. These differences are the result of using slightly more precise molecular weights in this analysis. 
Table 3.0-1

Number Densities (atoms/bn-cm) for $\mathrm{UF}_{4}+$ Oil with $100 \%$ Enriched Uranium

\begin{tabular}{|c|c|c|c|c|c|c|c|c||}
\hline $\begin{array}{c}\text { Vol Frac } \\
\text { Oil }\end{array}$ & $\begin{array}{c}\text { Vol Frac } \\
\text { UF4 }\end{array}$ & $\begin{array}{c}\mathrm{H} / \mathrm{U} \\
\text { Ratio }\end{array}$ & $\begin{array}{c}\mathrm{N} \\
\text { Carbon }\end{array}$ & $\begin{array}{c}\mathrm{N} \\
\text { Hydrogen }\end{array}$ & $\begin{array}{c}\mathrm{N} \\
\text { U-235 }\end{array}$ & $\begin{array}{c}\mathrm{N} \\
\text { U-238 }\end{array}$ & $\begin{array}{c}\mathrm{N} \\
\text { Fluorine }\end{array}$ & $\begin{array}{c}\text { U Density } \\
\text { gmU/cc }\end{array}$ \\
\hline 0.990 & 0.010 & 570.1 & 0.03698 & 0.07396 & 0.000130 & 0.000000 & 0.00052 & 0.05063 \\
\hline 0.970 & 0.030 & 186.2 & 0.03623 & 0.07246 & 0.000389 & 0.000000 & 0.00156 & 0.15189 \\
\hline 0.965 & 0.035 & 158.8 & 0.03604 & 0.07209 & 0.000454 & 0.000000 & 0.00182 & 0.17721 \\
\hline 0.960 & 0.040 & 138.2 & 0.03586 & 0.07172 & 0.000519 & 0.000000 & 0.00208 & 0.20252 \\
\hline 0.955 & 0.045 & 122.2 & 0.03567 & 0.07134 & 0.000584 & 0.000000 & 0.00233 & 0.22784 \\
\hline 0.950 & 0.050 & 109.4 & 0.03548 & 0.07097 & 0.000649 & 0.000000 & 0.00259 & 0.25315 \\
\hline 0.930 & 0.070 & 76.5 & 0.03474 & 0.06947 & 0.000908 & 0.000000 & 0.00363 & 0.35441 \\
\hline 0.910 & 0.090 & 58.2 & 0.03399 & 0.06798 & 0.001167 & 0.000000 & 0.00467 & 0.45567 \\
\hline 0.900 & 0.100 & 51.8 & 0.03362 & 0.06723 & 0.001297 & 0.000000 & 0.00519 & 0.50630 \\
\hline 0.890 & 0.110 & 46.6 & 0.03324 & 0.06649 & 0.001427 & 0.000000 & 0.00571 & 0.55693 \\
\hline 0.800 & 0.200 & 23.0 & 0.02988 & 0.05976 & 0.002594 & 0.000000 & 0.01038 & 1.01261 \\
\hline 0.700 & 0.300 & 13.4 & 0.02615 & 0.05229 & 0.003892 & 0.000000 & 0.01557 & 1.51891 \\
\hline 0.600 & 0.400 & 8.6 & 0.02241 & 0.04482 & 0.005189 & 0.000000 & 0.02076 & 2.02521 \\
\hline 0.500 & 0.500 & 5.8 & 0.01868 & 0.03735 & 0.006486 & 0.000000 & 0.02594 & 2.53152 \\
\hline 0.400 & 0.600 & 3.8 & 0.01494 & 0.02988 & 0.007783 & 0.000000 & 0.03113 & 3.03782 \\
\hline 0.300 & 0.700 & 2.5 & 0.01121 & 0.02241 & 0.009081 & 0.000000 & 0.03632 & 3.54413 \\
\hline 0.200 & 0.800 & 1.4 & 0.00747 & 0.01494 & 0.010378 & 0.000000 & 0.04151 & 4.05043 \\
\hline 0.100 & 0.900 & 0.6 & 0.00374 & 0.00747 & 0.011675 & 0.000000 & 0.04670 & 4.55673 \\
\hline \hline
\end{tabular}


Table 3.0-2

Number Densities (atoms/bn-cm) for $\mathrm{UF}_{4}+$ Oil with $97.7 \%$ Enriched Uranium

\begin{tabular}{||c|c|c|c|c|c|c|c|c||}
\hline $\begin{array}{c}\text { Vol Frac } \\
\text { Oil }\end{array}$ & $\begin{array}{c}\text { Vol Frac } \\
\text { UF4 }\end{array}$ & $\begin{array}{c}\text { H/U } \\
\text { Ratio }\end{array}$ & $\begin{array}{c}\mathrm{N} \\
\text { Carbon }\end{array}$ & $\begin{array}{c}\mathrm{N} \\
\text { Hydrogen }\end{array}$ & $\begin{array}{c}\mathrm{N} \\
\text { U-235 }\end{array}$ & $\begin{array}{c}\mathrm{N} \\
\text { U-238 }\end{array}$ & $\begin{array}{c}\mathrm{N} \\
\text { Fluorine }\end{array}$ & gmU/cc \\
\hline \hline 0.990 & 0.010 & 570.2 & 0.03698 & 0.07396 & 0.000127 & 0.000003 & 0.00052 & 0.05063 \\
\hline 0.970 & 0.030 & 186.2 & 0.03623 & 0.07246 & 0.000380 & 0.000009 & 0.00156 & 0.15190 \\
\hline 0.965 & 0.035 & 158.8 & 0.03604 & 0.07209 & 0.000444 & 0.000010 & 0.00182 & 0.17722 \\
\hline 0.960 & 0.040 & 138.2 & 0.03586 & 0.07172 & 0.000507 & 0.000012 & 0.00208 & 0.20254 \\
\hline 0.955 & 0.045 & 122.2 & 0.03567 & 0.07134 & 0.000570 & 0.000013 & 0.00233 & 0.22785 \\
\hline 0.950 & 0.050 & 109.4 & 0.03548 & 0.07097 & 0.000634 & 0.000015 & 0.00259 & 0.25317 \\
\hline 0.930 & 0.070 & 76.5 & 0.03474 & 0.06947 & 0.000887 & 0.000021 & 0.00363 & 0.35444 \\
\hline 0.910 & 0.090 & 58.2 & 0.03399 & 0.06798 & 0.001141 & 0.000027 & 0.00467 & 0.45571 \\
\hline 0.900 & 0.100 & 51.8 & 0.03362 & 0.06723 & 0.001267 & 0.000029 & 0.00519 & 0.50634 \\
\hline 0.890 & 0.110 & 46.6 & 0.03324 & 0.06649 & 0.001394 & 0.000032 & 0.00571 & 0.55697 \\
\hline 0.800 & 0.200 & 23.0 & 0.02988 & 0.05976 & 0.002535 & 0.000059 & 0.01038 & 1.01268 \\
\hline 0.700 & 0.300 & 13.4 & 0.02615 & 0.05229 & 0.003802 & 0.000088 & 0.01556 & 1.51902 \\
\hline 0.600 & 0.400 & 8.6 & 0.02241 & 0.04482 & 0.005070 & 0.000118 & 0.02075 & 2.02536 \\
\hline 0.500 & 0.500 & 5.8 & 0.01868 & 0.03735 & 0.006337 & 0.000147 & 0.02594 & 2.53170 \\
\hline 0.400 & 0.600 & 3.8 & 0.01494 & 0.02988 & 0.007605 & 0.000177 & 0.03113 & 3.03804 \\
\hline 0.300 & 0.700 & 2.5 & 0.01121 & 0.02241 & 0.008872 & 0.000206 & 0.03631 & 3.54438 \\
\hline 0.200 & 0.800 & 1.4 & 0.00747 & 0.01494 & 0.010140 & 0.000236 & 0.04150 & 4.05072 \\
\hline 0.100 & 0.900 & 0.6 & 0.00374 & 0.00747 & 0.011407 & 0.000265 & 0.04669 & 4.55706 \\
\hline \hline
\end{tabular}


Table 3.0-3

Number Densities (atoms/bn-cm) for $\mathrm{UF}_{4}+$ Oil with $90.0 \%$ Enriched Uranium

\begin{tabular}{|c|c|c|c|c|c|c|c|c|}
\hline $\begin{array}{c}\text { Vol Frac } \\
\text { Oil }\end{array}$ & $\begin{array}{c}\text { Vol Frac } \\
\text { UF4 }\end{array}$ & $\begin{array}{c}\text { H/U } \\
\text { Ratio }\end{array}$ & $\begin{array}{c}\mathrm{N} \\
\text { Carbon }\end{array}$ & $\begin{array}{c}\mathrm{N} \\
\text { Hydrogen }\end{array}$ & $\begin{array}{c}\mathrm{N} \\
\text { U-235 }\end{array}$ & $\begin{array}{c}\mathrm{N} \\
\text { U-238 }\end{array}$ & $\begin{array}{c}\mathrm{N} \\
\text { Fluorine }\end{array}$ & gmU/cc \\
\hline 0.990 & 0.010 & 570.7 & 0.03698 & 0.07396 & 0.000117 & 0.000013 & 0.00052 & 0.05065 \\
\hline 0.970 & 0.030 & 186.4 & 0.03623 & 0.07246 & 0.000350 & 0.000038 & 0.00156 & 0.15194 \\
\hline 0.965 & 0.035 & 158.9 & 0.03604 & 0.07209 & 0.000409 & 0.000045 & 0.00181 & 0.17726 \\
\hline 0.960 & 0.040 & 138.3 & 0.03586 & 0.07172 & 0.000467 & 0.000051 & 0.00207 & 0.20258 \\
\hline 0.955 & 0.045 & 122.3 & 0.03567 & 0.07134 & 0.000526 & 0.000058 & 0.00233 & 0.22791 \\
\hline 0.950 & 0.050 & 109.5 & 0.03548 & 0.07097 & 0.000584 & 0.000064 & 0.00259 & 0.25323 \\
\hline 0.930 & 0.070 & 76.6 & 0.03474 & 0.06947 & 0.000817 & 0.000090 & 0.00363 & 0.35452 \\
\hline 0.910 & 0.090 & 58.3 & 0.03399 & 0.06798 & 0.001051 & 0.000115 & 0.00467 & 0.45581 \\
\hline 0.900 & 0.100 & 51.9 & 0.03362 & 0.06723 & 0.001168 & 0.000128 & 0.00518 & 0.50646 \\
\hline 0.890 & 0.110 & 46.6 & 0.03324 & 0.06649 & 0.001285 & 0.000141 & 0.00570 & 0.55711 \\
\hline 0.800 & 0.200 & 23.1 & 0.02988 & 0.05976 & 0.002336 & 0.000256 & 0.01037 & 1.01292 \\
\hline 0.700 & 0.300 & 13.4 & 0.02615 & 0.05229 & 0.003504 & 0.000384 & 0.01555 & 1.51938 \\
\hline 0.600 & 0.400 & 8.6 & 0.02241 & 0.04482 & 0.004671 & 0.000512 & 0.02074 & 2.02584 \\
\hline 0.500 & 0.500 & 5.8 & 0.01868 & 0.03735 & 0.005839 & 0.000641 & 0.02592 & 2.53230 \\
\hline 0.400 & 0.600 & 3.8 & 0.01494 & 0.02988 & 0.007007 & 0.000769 & 0.03110 & 3.03876 \\
\hline 0.300 & 0.700 & 2.5 & 0.01121 & 0.02241 & 0.008175 & 0.000897 & 0.03629 & 3.54522 \\
\hline 0.200 & 0.800 & 1.4 & 0.00747 & 0.01494 & 0.009343 & 0.001025 & 0.04147 & 4.05168 \\
\hline 0.100 & 0.900 & 0.6 & 0.00374 & 0.00747 & 0.010511 & 0.001153 & 0.04666 & 4.55814 \\
\hline
\end{tabular}


Table 3.0-4

Number Densities (atoms/bn-cm) for $\mathrm{UF}_{4}+$ Oil with $80.0 \%$ Enriched Uranium

\begin{tabular}{||c|c|c|c|c|c|c|c|c||}
\hline $\begin{array}{c}\text { Vol Frac } \\
\text { Oil }\end{array}$ & $\begin{array}{c}\text { Vol.Frac } \\
\text { UF4 }\end{array}$ & $\begin{array}{c}\text { H/U } \\
\text { Ratio }\end{array}$ & $\begin{array}{c}\mathrm{N} \\
\text { Carbon }\end{array}$ & $\begin{array}{c}\mathrm{N} \\
\text { Hydrogen }\end{array}$ & $\begin{array}{c}\mathrm{N} \\
\text { U-235 }\end{array}$ & $\begin{array}{c}\mathrm{N} \\
\text { U-238 }\end{array}$ & $\begin{array}{c}\mathrm{N} \\
\text { Fluorine }\end{array}$ & gmU/cc \\
\hline 0.990 & 0.010 & 571.2 & 0.03698 & 0.07396 & 0.000104 & 0.000026 & 0.00052 & 0.05066 \\
\hline 0.970 & 0.030 & 186.6 & 0.03623 & 0.07246 & 0.000312 & 0.000077 & 0.00155 & 0.15198 \\
\hline 0.965 & 0.035 & 159.1 & 0.03604 & 0.07209 & 0.000363 & 0.000090 & 0.00181 & 0.17732 \\
\hline 0.960 & 0.040 & 138.5 & 0.03586 & 0.07172 & 0.000415 & 0.000103 & 0.00207 & 0.20265 \\
\hline 0.955 & 0.045 & 122.4 & 0.03567 & 0.07134 & 0.000467 & 0.000115 & 0.00233 & 0.22798 \\
\hline 0.950 & 0.050 & 109.6 & 0.03548 & 0.07097 & 0.000519 & 0.000128 & 0.00259 & 0.25331 \\
\hline 0.930 & 0.070 & 76.7 & 0.03474 & 0.06947 & 0.000727 & 0.000179 & 0.00363 & 0.35463 \\
\hline 0.910 & 0.090 & 58.3 & 0.03399 & 0.06798 & 0.000935 & 0.000231 & 0.00466 & 0.45595 \\
\hline 0.900 & 0.100 & 51.9 & 0.03362 & 0.06723 & 0.001038 & 0.000256 & 0.00518 & 0.50662 \\
\hline 0.890 & 0.110 & 46.7 & 0.03324 & 0.06649 & 0.001142 & 0.000282 & 0.00570 & 0.55728 \\
\hline 0.800 & 0.200 & 23.1 & 0.02988 & 0.05976 & 0.002077 & 0.000513 & 0.01036 & 1.01323 \\
\hline 0.700 & 0.300 & 13.5 & 0.02615 & 0.05229 & 0.003115 & 0.000769 & 0.01554 & 1.51985 \\
\hline 0.600 & 0.400 & 8.7 & 0.02241 & 0.04482 & 0.004154 & 0.001025 & 0.02072 & 2.02647 \\
\hline 0.500 & 0.500 & 5.8 & 0.01868 & 0.03735 & 0.005192 & 0.001282 & 0.02589 & 2.53308 \\
\hline 0.400 & 0.600 & 3.8 & 0.01494 & 0.02988 & 0.006230 & 0.001538 & 0.03107 & 3.03970 \\
\hline 0.300 & 0.700 & 2.5 & 0.01121 & 0.02241 & 0.007269 & 0.001794 & 0.03625 & 3.54631 \\
\hline 0.200 & 0.800 & 1.4 & 0.00747 & 0.01494 & 0.008307 & 0.002051 & 0.04143 & 4.05293 \\
\hline 0.100 & 0.900 & 0.6 & 0.00374 & 0.00747 & 0.009346 & 0.002307 & 0.04661 & 4.55955 \\
\hline
\end{tabular}


Table 3.0-5

Number Densities (atoms/bn-cm) for $\mathrm{UF}_{4}+$ Oil with $70.0 \%$ Enriched Uranium

\begin{tabular}{|c|c|c|c|c|c|c|c|c||}
\hline $\begin{array}{c}\text { Vol Frac } \\
\text { Oil }\end{array}$ & $\begin{array}{c}\text { Vol Frac } \\
\text { UF4 }\end{array}$ & $\begin{array}{c}\mathrm{H} / \mathrm{U} \\
\text { Ratio }\end{array}$ & $\begin{array}{c}\mathrm{N} \\
\text { Carbon }\end{array}$ & $\begin{array}{c}\mathrm{N} \\
\text { Hydrogen }\end{array}$ & $\begin{array}{c}\mathrm{N} \\
\mathrm{U}-235\end{array}$ & $\begin{array}{c}\mathrm{N} \\
\text { U-238 }\end{array}$ & $\begin{array}{c}\mathrm{N} \\
\text { Fluorine }\end{array}$ & gmU/cc \\
\hline \hline 0.990 & 0.010 & 571.8 & 0.03698 & 0.07396 & 0.000091 & 0.000038 & 0.00052 & 0.05068 \\
\hline 0.970 & 0.030 & 186.7 & 0.03623 & 0.07246 & 0.000273 & 0.000115 & 0.00155 & 0.15203 \\
\hline 0.965 & 0.035 & 159.2 & 0.03604 & 0.07209 & 0.000318 & 0.000135 & 0.00181 & 0.17737 \\
\hline 0.960 & 0.040 & 138.6 & 0.03586 & 0.07172 & 0.000364 & 0.000154 & 0.00207 & 0.20271 \\
\hline 0.955 & 0.045 & 122.6 & 0.03567 & 0.07134 & 0.000409 & 0.000173 & 0.00233 & 0.22805 \\
\hline 0.950 & 0.050 & 109.7 & 0.03548 & 0.07097 & 0.000454 & 0.000192 & 0.00259 & 0.25339 \\
\hline 0.930 & 0.070 & 76.7 & 0.03474 & 0.06947 & 0.000636 & 0.000269 & 0.00362 & 0.35474 \\
\hline 0.910 & 0.090 & 58.4 & 0.03399 & 0.06798 & 0.000818 & 0.000346 & 0.00466 & 0.45610 \\
\hline 0.900 & 0.100 & 52.0 & 0.03362 & 0.06723 & 0.000909 & 0.000385 & 0.00517 & 0.50677 \\
\hline 0.890 & 0.110 & 46.7 & 0.03324 & 0.06649 & 0.001000 & 0.000423 & 0.00569 & 0.55745 \\
\hline 0.800 & 0.200 & 23.1 & 0.02988 & 0.05976 & 0.001818 & 0.000769 & 0.01035 & 1.01355 \\
\hline 0.700 & 0.300 & 13.5 & 0.02615 & 0.05229 & 0.002727 & 0.001154 & 0.01552 & 1.52032 \\
\hline 0.600 & 0.400 & 8.7 & 0.02241 & 0.04482 & 0.003636 & 0.001538 & 0.02070 & 2.02709 \\
\hline 0.500 & 0.500 & 5.8 & 0.01868 & 0.03735 & 0.004544 & 0.001923 & 0.02587 & 2.53386 \\
\hline 0.400 & 0.600 & 3.9 & 0.01494 & 0.02988 & 0.005453 & 0.002308 & 0.03104 & 3.04064 \\
\hline 0.300 & 0.700 & 2.5 & 0.01121 & 0.02241 & 0.006362 & 0.002692 & 0.03622 & 3.54741 \\
\hline 0.200 & 0.800 & 1.4 & 0.00747 & 0.01494 & 0.007271 & 0.003077 & 0.04139 & 4.05418 \\
\hline 0.100 & 0.900 & 0.6 & 0.00374 & 0.00747 & 0.008180 & 0.003461 & 0.04657 & 4.56096 \\
\hline \hline
\end{tabular}




\section{Table 3.0-6}

Number Densities (atoms/bn-cm) for $\mathrm{UF}_{4}+$ Oil with $60 \%$ Enriched Uranium

\begin{tabular}{|c|c|c|c|c|c|c|c|c||}
\hline $\begin{array}{c}\text { Vol Frac } \\
\text { Oil }\end{array}$ & $\begin{array}{c}\text { Vol Frac } \\
\text { UF4 }\end{array}$ & $\begin{array}{c}\text { R/U } \\
\text { Ratio }\end{array}$ & $\begin{array}{c}\mathrm{N} \\
\text { Carbon }\end{array}$ & $\begin{array}{c}\mathrm{N} \\
\text { Hydrogen }\end{array}$ & $\begin{array}{c}\mathrm{N} \\
\text { U-235 }\end{array}$ & $\begin{array}{c}\mathrm{N} \\
\text { U-238 }\end{array}$ & $\begin{array}{c}\mathrm{N} \\
\text { Fluorine }\end{array}$ & gmU/cc \\
\hline \hline 0.990 & 0.010 & 572.3 & 0.03698 & 0.07396 & 0.000078 & 0.000051 & 0.00052 & 0.05069 \\
\hline 0.970 & 0.030 & 186.9 & 0.03623 & 0.07246 & 0.000234 & 0.000154 & 0.00155 & 0.15208 \\
\hline 0.965 & 0.035 & 159.4 & 0.03604 & 0.07209 & 0.000273 & 0.000180 & 0.00181 & 0.17743 \\
\hline 0.960 & 0.040 & 138.7 & 0.03586 & 0.07172 & 0.000312 & 0.000205 & 0.00207 & 0.20277 \\
\hline 0.955 & 0.045 & 122.7 & 0.03567 & 0.07134 & 0.000351 & 0.000231 & 0.00233 & 0.22812 \\
\hline 0.950 & 0.050 & 109.8 & 0.03548 & 0.07097 & 0.000390 & 0.000256 & 0.00258 & 0.25346 \\
\hline 0.930 & 0.070 & 76.8 & 0.03474 & 0.06947 & 0.000546 & 0.000359 & 0.00362 & 0.35485 \\
\hline 0.910 & 0.090 & 58.5 & 0.03399 & 0.06798 & 0.000701 & 0.000462 & 0.00465 & 0.45624 \\
\hline 0.900 & 0.100 & 52.0 & 0.03362 & 0.06723 & 0.000779 & 0.000513 & 0.00517 & 0.50693 \\
\hline 0.890 & 0.110 & 46.8 & 0.03324 & 0.06649 & 0.000857 & 0.000564 & 0.00569 & 0.55762 \\
\hline 0.800 & 0.200 & 23.1 & 0.02988 & 0.05976 & 0.001559 & 0.001026 & 0.01034 & 1.01386 \\
\hline 0.700 & 0.300 & 13.5 & 0.02615 & 0.05229 & 0.002338 & 0.001539 & 0.01551 & 1.52079 \\
\hline 0.600 & 0.400 & 8.7 & 0.02241 & 0.04482 & 0.003117 & 0.002052 & 0.02068 & 2.02772 \\
\hline 0.500 & 0.500 & 5.8 & 0.01868 & 0.03735 & 0.003896 & 0.002565 & 0.02585 & 2.53465 \\
\hline 0.400 & 0.600 & 3.9 & 0.01494 & 0.02988 & 0.004676 & 0.003078 & 0.03101 & 3.04158 \\
\hline 0.300 & 0.700 & 2.5 & 0.01121 & 0.02241 & 0.005455 & 0.003591 & 0.03618 & 3.54851 \\
\hline 0.200 & 0.800 & 1.4 & 0.00747 & 0.01494 & 0.006234 & 0.004104 & 0.04135 & 4.05544 \\
\hline 0.100 & 0.900 & 0.6 & 0.00374 & 0.00747 & 0.007014 & 0.004617 & 0.04652 & 4.56236 \\
\hline \hline
\end{tabular}




\subsection{Results}

\subsection{32-inch-Diameter by 50-inch-tall Polyethylene Bottle}

This section presents additional calculations for the "744G" container, described in Table 1.0.1. The "OG" container is bounded as well by these calculations, because it has the same inner diameter, but is only 24 instead of 50 inches tall. The results presented in Reference 1 demonstrated that the $\mathrm{k}_{\text {eff }}+2 \sigma<.95$ criteria was met for both the $\mathrm{UO}_{2} \mathrm{~F}_{2}+\mathrm{H}_{2} \mathrm{O}$ and $\mathrm{UF}_{4}+$ Oil materials for all contingency cases except the TACW case, which violated for both materials. In comparing Reference 1 Figures 4.3.1-3 and 4.3.1-7, it is seen that the $\mathrm{UF}_{4}+$ Oil case is clearly more reactive. The Figure 4.3.1-3 results for $\mathrm{H} / \mathrm{U}$ cases between 3 and 4 are overly conservative because there was no credit taken for the maximum value of $3.2 \mathrm{gU} / \mathrm{cc}$ in this particular case. Therefore, it was decided to rerun the $\mathrm{UF}_{4}+$ Oil TACW cases using the revised TACW assumptions described in Section 2.2.5. The range of $\mathrm{H} / \mathrm{U}$ was limited to between 23 and 77 since Reference 1 Figure 4.3.1-7 clearly indicates that the optimum $\mathrm{H} / \mathrm{U}$ falls somewhere in this range. The results from the additional calculations are tabulated and plotted in Figure 4.1-1. The significant changes from the Reference 1 TACW calculations are:

- Container walls (.195" thick) are modeled, making the $\mathrm{K}_{\text {eff }}$ higher.

- $100 \mathrm{Kg}$ person is moved back $2^{\prime \prime}$ from the two containers.

- Hands are modeled as 6" high, centered on the container.

- The number of neutron generations was set to 303 instead of 103.

- The number of neutrons per generation was set to 600 instead of 300 .

- The $\mathrm{UF}_{4}+$ Oil number densities from Table 3.0-1 were used.

The results shown in Figure 4.1-1 indicate that the safety criteria is met for the TACW contingency geometry. Therefore, the 744G and OG containers meet the double contingency requirements, and may be approved for storage of uranium bearing materials without any restrictions on mass or assay. 
Figure 4.1-1

Two 4.32" ID x 50" Tall Cylinders of $\mathrm{UF}_{4}$ and Oil Next to a Wall

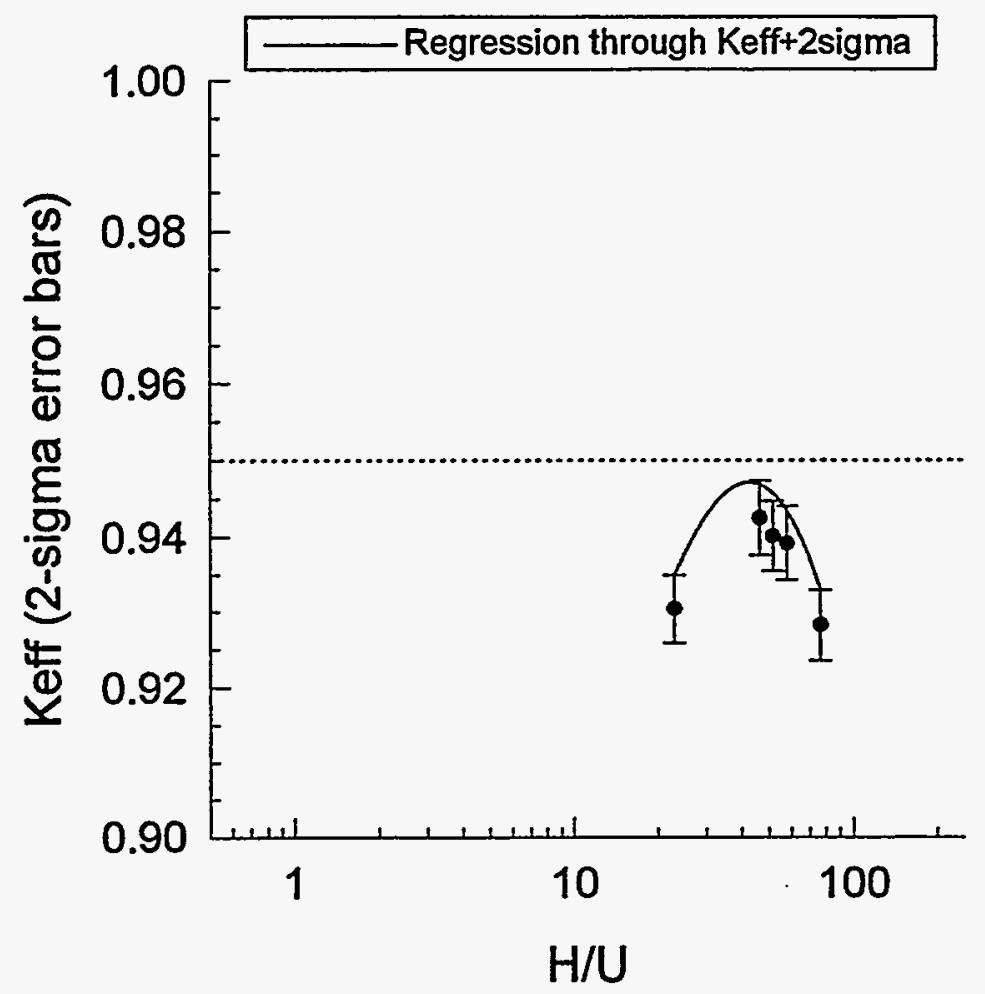

Two 4.32 in. Diameter Poly Containers Adjacent to Concrete Wall for $100 \%$ Enriched UF4+Oil

\begin{tabular}{||c|c|c|c|c|c||}
\hline Case & $H / U$ & Keff & $\sigma$ & $2 \sigma$ & Keff $+2 \sigma$ \\
\hline tacw23 & 23.0 & 0.93031 & 0.00227 & 0.00454 & 0.93485 \\
\hline tacw47 & 46.6 & 0.94248 & 0.00244 & 0.00488 & 0.94736 \\
\hline tacw52 & 51.8 & 0.94007 & 0.00231 & 0.00462 & 0.94469 \\
\hline tacw58 & 58.2 & 0.93913 & 0.00244 & 0.00488 & 0.94401 \\
\hline tacw77 & 76.5 & 0.92813 & 0.00237 & 0.00474 & 0.93287 \\
\hline
\end{tabular}




\subsection{0-inch-Diameter by 24-inch-Tall Polyethylene Container}

This section presents additional calculations for the "GP Container" and "24-in Polybottle" described in Table 1.0-1. The 24-inch Polybottle is more limiting because it has slightly thicker walls (.1875 versus .13 inches) and is .25 inches taller. It is also more limiting because the lid of the GP container acts as a spacer to limit interaction with other containers. The GP container lid is a minimum of 6.63 inches in outer diameter. In general, the additional calculations are performed for a 24-inch Polybottle, except for certain TACW geometry cases, where credit is taken for the GP container lid dimensions. The intent of these calculations is to qualify GP containers for single unit storage next to concrete walls, while administratively restricting such storage for 24-inch polybottles.

The results from Reference 1 indicate that for $\mathrm{UO}_{2} \mathrm{~F}_{2}+\mathrm{H}_{2} \mathrm{O}$, the criticality safety criteria is met for all contingency cases except the TACW case. Revised TACW calculations were performed using $100 \%$ enriched $\mathrm{UO}_{2} \mathrm{~F}_{2}+\mathrm{H}_{2} \mathrm{O}$ at several limiting $\mathrm{H} / \mathrm{U}$ ratios. The calculations are tabulated and plotted in Figure 4.2-1, and include the following significant changes from Reference 1:

- Container walls (.1875" thick) are modeled, increasing the K-effective.

- $100 \mathrm{Kg}$ person is moved back $2 "$ from the two containers.

- Hands are modeled as 6" high, centered on the container.

- There are $3^{\prime \prime}$ of POLY on top of each fissile cylinder, simulating the lid.

- Credit is taken for the GP container lid outer diameter of 6.63", even though the full diameter of the lid was not modeled due to KENO-Va geometry limitations. A spacing of $1.63^{\prime \prime}$ is maintained between the fissile material in the two cylinders, and a spacing of $.815^{\prime \prime}$ is maintained between the fissile material and the concrete wall.

- Cases with $\mathrm{H} / \mathrm{U}$ less than 4 are based on a maximum Uranium density of 3.2 $\mathrm{gU} / \mathrm{cc}$.

Since the results in Figure 4.2-1 indicate that the criticality safety criteria is met for this case, the conclusion is made that the GP container is safe for storage of $\mathrm{UO}_{2} \mathrm{~F}_{2}+\mathrm{H}_{2} \mathrm{O}$ at any enrichment and $\mathrm{H} / \mathrm{U}$. The 24-inch Polybottle is also safe for this material, providing an administrative restriction is in place prohibiting storage of single 24inch polybottles within 1 foot of concrete walls.

In the case of $\mathrm{UF}_{4}+$ Oil, the results presented in Reference 1 indicate that the 5 -inch diameter containers do not meet the criticality safety criteria for any single unit geometry at $100 \%$ enrichment. This indicates that a mass and/or assay limit is required if the containers are to be qualified for storage of material containing uranium and oil. An assay limit of $80 \%$ has been selected, based on scoping calculations. The Single Fully Reflected (SFR) cases were rerun with $80 \%$ enriched $\mathrm{UF}_{4}+$ Oil for a full range of $\mathrm{H} / \mathrm{U}$ ratios. These results are tabulated and plotted in Figure 4.2-2. The only change in these cases from Reference 1 is the reduced enrichment. The results from Figure 4.2-2 indicate that the safety criteria is met for the SFR geometry when the $\mathrm{UF}_{4}+$ Oil assay is limited to $80 \%$. The results also indicate that the optimal $\mathrm{H} / \mathrm{U}$ ratio is in the vicinity of 50 for this material. 
The analysis for $80 \%$ enriched $\mathrm{UF}_{4}+$ Oil in 5 -inch diameter containers is completed by executing the remaining contingency and array cases at $\mathrm{H} / \mathrm{U}$ ratios near the optimum value. These cases are tabulated in Figure 4.2-3. Aside from the use of $80 \%$ enrichment, the following changes are made in these calculations from Reference 1:

- Container walls (.1875" thick) are modeled, increasing the K-effective.

- $100 \mathrm{Kg}$ person is moved back 2" from the two containers (TACW geometry only). - Hands are modeled as 6" high, centered on the container (TACW geometry only).

- There are 3" of POLY on top of each fissile cylinder, simulating the lid.

- Credit is taken for the GP container lid outer diameter of 6.63", even though the full diameter of the lid was not modeled due to KENO-Va geometry limitations. A spacing of 1.63" is maintained between the fissile material in the two cylinders, and a spacing of $.815^{\prime \prime}$ is maintained between the fissile material and the concrete wall (TACW geometry only).

Since the results in Figure 4.2-3 indicate that the criticality safety criteria is met for these cases, the conclusion is made that the GP container is safe for storage of $\mathbf{U F}_{4}+$ Oil up to $80 \%$ enrichment. Should it become necessary to store greater than $80 \%$ enriched $\mathrm{UF}_{4}+$ Oil in these containers, further analysis will be required to determine a safe uranium mass limit. The 24-inch Polybottle is also safe for the same material, providing an administrative restriction is in place prohibiting storage of single 24inch polybottles within 1 foot of concrete walls.

The additional contingency of misloading one of the 5 inch ID containers with the most reactive known substance (100\% enriched $\mathrm{UF}_{4}+$ Oil) and assuming nominal reflection (SMRC) is addressed in Reference 1, Figure 4.4.3-1. The results indicate that the criticality safety criteria is still met. 
POEF-SH-43

Figure 4.2-1

Two 5.0" ID $\times 24^{\prime \prime}$ Tall Cylinders of $\mathrm{UO}_{2} \mathrm{~F}_{2}$ and Water Next to a Wall

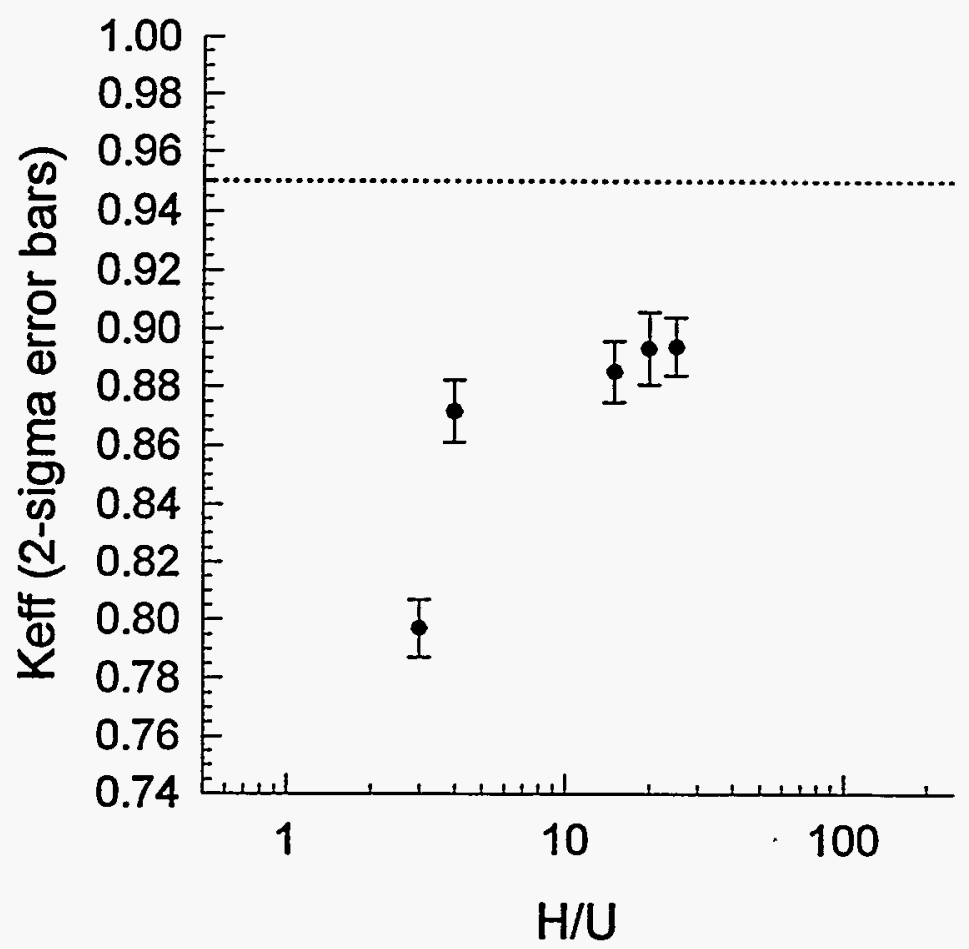

\begin{tabular}{|c|c|c|c|c|c|}
\hline \multicolumn{6}{|c|}{$\begin{array}{l}\text { Two } 5.0 \text { in. Diameter Poly Containers Adjacent to Concrete Wall } \\
\text { for } 100 \% \text { Enriched UO2F } 2+\text { Water }\end{array}$} \\
\hline Case & $\mathrm{H} / \mathrm{U}$ & Keff & $\sigma$ & $2 \sigma$ & Keff $+2 \sigma$ \\
\hline$z 100 a$ & 3.0 & 0.79698 & 0.00489 & 0.00978 & 0.80676 \\
\hline$z 100 b$ & 3.99 & 0.87156 & 0.00523 & 0.01046 & 0.88202 \\
\hline$z 100 c$ & 15.0 & 0.88516 & 0.00530 & 0.01060 & 0.89576 \\
\hline$z 100 d$ & 20.0 & 0.89311 & 0.00620 & 0.01240 & 0.90551 \\
\hline$z 100 e$ & 25.0 & 0.89376 & 0.00501 & 0.01002 & 0.90378 \\
\hline
\end{tabular}


Figure 4.2-2

Single Fully Reflected $5.00^{\prime \prime}$ ID $\times 24^{\prime \prime}$ Tall Cylinder of $80 \%$ Enriched $\mathrm{UF}_{4}$ and Oil

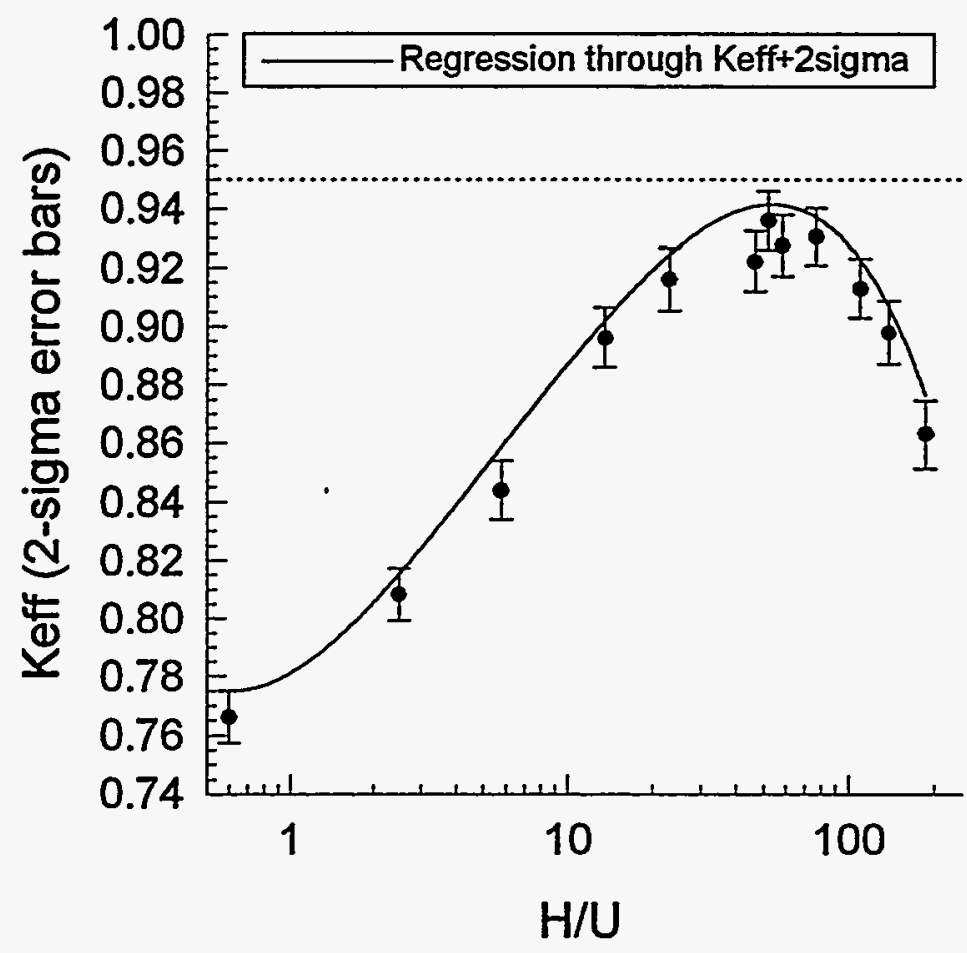

\begin{tabular}{|c|c|c|c|c|c|}
\hline \multicolumn{6}{|c|}{$\begin{array}{l}\text { Single } 5.0 \text { in. Diameter Poly. Container with Full Reflection } \\
\text { for } 80 \% \text { Enriched UF4+Oil }\end{array}$} \\
\hline Case & $H / U$ & Keff & $\sigma$ & $2 \sigma$ & Keff $+2 \sigma$ \\
\hline x800r & 0.6 & 0.76603 & 0.00442 & 0.00884 & 0.77487 \\
\hline$x 800 p$ & 2.5 & 0.80816 & 0.00448 & 0.00896 & 0.81712 \\
\hline$x 800 n$ & 5.8 & 0.84375 & 0.00499 & 0.00998 & 0.85373 \\
\hline$\times 8001$ & 13.5 & 0.89612 & 0.00512 & 0.01024 & 0.90636 \\
\hline$\times 800 k$ & 23.1 & 0.91598 & 0.00534 & 0.01068 & 0.92666 \\
\hline$\times 800 j$ & 46.7 & 0.92217 & 0.00514 & 0.01028 & 0.93245 \\
\hline$x 800 i$ & 51.9 & 0.93600 & 0.00496 & 0.00992 & 0.94592 \\
\hline x800h & 58.3 & 0.92754 & 0.00519 & 0.01038 & 0.93792 \\
\hline$\times 800 \mathrm{~g}$ & 76.7 & 0.93057 & 0.00482 & 0.00964 & 0.94021 \\
\hline$x 800 f$ & 109.6 & 0.91294 & 0.00504 & 0.01008 & 0.92302 \\
\hline x800d & 138.5 & 0.89791 & 0.00541 & 0.01082 & 0.90873 \\
\hline$x 800 b$ & 186.6 & 0.86301 & 0.00586 & 0.01172 & 0.87473 \\
\hline
\end{tabular}


Figure 4.2-3

Contingency and Array Cases for 5.0" ID x 24" Tall Cylinders of $80 \%$ Enriched UF and Oil

\begin{tabular}{|l|l|c|c|c|c|c||}
\hline \multicolumn{6}{|l}{5.0 in. Diameter Poly. Container Contingency and Array Cases } \\
for 80\% Enriched UF4+ Oil \\
\hline Case & Geometry & H/U & Keff & $\sigma$ & $2 \sigma$ & Keff $+2 \sigma$ \\
\hline z800h & TACW* & 58.3 & 0.91621 & 0.00492 & 0.00984 & 0.92605 \\
\hline z800i & TACW* & 51.9 & 0.91528 & 0.00545 & 0.01090 & 0.92618 \\
\hline z800j & TACW* & 46.7 & 0.92138 & 0.00518 & 0.01036 & 0.93174 \\
\hline & & & & & & \\
\hline y800h & SCC & 58.3 & 0.91648 & 0.00521 & 0.01042 & 0.92690 \\
\hline y800i & SCC & 51.9 & 0.92384 & 0.00564 & 0.01128 & 0.93512 \\
\hline y800j & SCC & 46.7 & 0.92003 & 0.00589 & 0.01178 & 0.93181 \\
\hline & & & & & & \\
\hline w800h & TSCW & 58.3 & 0.91810 & 0.00520 & 0.01040 & 0.92850 \\
\hline w800i & TSCW & 51.9 & 0.90376 & 0.00566 & 0.01132 & 0.91508 \\
\hline w800j & TSCW & 46.7 & 0.91389 & 0.00595 & 0.01190 & 0.92579 \\
\hline & & & & & & \\
\hline v800h & ACE & 58.3 & 0.82582 & 0.00301 & 0.00602 & 0.83184 \\
\hline v800i & ACE & 51.9 & 0.82184 & 0.00304 & 0.00608 & 0.82792 \\
\hline v800j & ACE & 46.7 & 0.82700 & 0.00300 & 0.00600 & 0.83300 \\
\hline & & & & & & \\
\hline u800h & AOSP & 58.3 & 0.82077 & 0.00324 & 0.00648 & 0.82725 \\
\hline u800i & AOSP & 51.9 & 0.83021 & 0.00323 & 0.00646 & 0.83667 \\
\hline u800j & AOSP & 46.7 & 0.82923 & 0.00286 & 0.00572 & 0.83495 \\
\hline & & & & & & \\
\hline
\end{tabular}

* The TACW cases in the above table take credit for the GP lid outer diameter of 6.63 inches. Without the GP lid, the Keff $+2 \sigma$ for the $H / U=51.9$ case becomes .99528 . 


\subsection{25-inch-Diameter by 24-inch-Tall Steel Container (F-can)}

This section presents additional calculations for the "F-can" container described in Table 1.0-1. The results in Reference 1 indicated that the F-can did not meet the criticality safety criteria for any of the $100 \%$ enrichment cases analyzed. Therefore, an extensive reanalysis of the F-can was performed, in order to establish safe mass and assay limits. As a result of the extensive amount of material already being stored in $\mathrm{F}$-cans, it was necessary to quantify separate safe mass limits for both $\mathrm{UO}_{2} \mathrm{~F}_{2}+\mathrm{H}_{2} \mathrm{O}$ and $\mathrm{UF}_{4}+\mathrm{Oil}$. It was also necessary to complete the array calculations for the F-can, since these had not been performed in Reference 1.

The standard room (SR) assumptions were relaxed in the case of F-cans, in order to reach acceptable mass and assay limits. Specifically, the dimensions on the concrete floor were assumed to be 12 inches instead of 24 inches, and the concrete wall dimensions were assumed to be 4 inches instead of 12 inches. The change to the floor dimension is not significant with respect to the results, because concrete reflectors are essentially infinite after approximately 10 inches. Therefore, it is judged that additional restrictions are not required because of the assumed floor dimension. However, the concrete wall dimension of 4 inches significantly reduces the neutron reflection from the wall in the TACW and SCC cases. Therefore, an administrative restriction is required to prevent the storage of $\mathrm{F}$-cans near concrete walls which are more than 4 inches in effective thickness. The effective thickness for walls made out of concrete block can be calculated by dividing the cross sectional area of the concrete (in a plane perpendicular to the wall, and excluding any air voids) by the block width. It is expected that standard concrete block walls will have an effective thickness less than 4 inches.

\subsubsection{Safe Storage of $\mathrm{UO}_{2} \mathrm{~F}_{2}$ in an F-can}

Number densities were generated for $\mathrm{UO}_{2} \mathrm{~F}_{2}+\mathrm{H}_{2} \mathrm{O}$ using the NUMDEN code, and assuming a maximum enrichment of $97.7 \%$. The Single Fully Reflected (SFR) cases were then rerun for a full range of $\mathrm{H} / \mathrm{U}$ ratios at this enrichment. These results are tabulated and plotted in Figure 4.3.1-1. The results from Figure 4.3.1-1 indicate that the $\mathrm{K}_{\text {eff }}+2 \sigma<.95$ criteria is violated at the optimum $\mathrm{H} / \mathrm{U}$ ratio of 25 . However, an acceptable result was obtained for the $\mathrm{H} / \mathrm{U}=40$ case, which corresponds to a uranium mass of 5040 grams in the F-can. The $\mathrm{H} / \mathrm{U}=25$ case was rerun with an enrichment of $90 \%$ (see Figure 4.3.1-1, case a900d), and the criticality safety criteria was met. These results form the basis for restricting the allowable $\mathrm{UO}_{2} \mathrm{~F}_{2}$ uranium mass to less than $5000 \mathrm{gmU}$ when the assay exceeds $90 \%$. Below $90 \%$ enrichment, the uranium mass may remain unrestricted for $\mathrm{UO}_{2} \mathrm{~F}_{2}$.

The analysis for $\mathrm{UO}_{2} \mathrm{~F}_{2}$ in an $\mathrm{F}$-can is completed by executing the remaining contingency and array cases. The SCC, TACW, ACE, ACE-F, and AOSP geometries are analyzed assuming $97.7 \%$ enrichment and an $\mathrm{H} / \mathrm{U}$ of 40 , because this material will be permitted by the mass limit, and is more reactive than the $90 \%$ enriched material at the optimum $\mathrm{H} / \mathrm{U}$ of 25. In addition, the SFR-SHORT and TACW-SHORT geometries are analyzed to 
account for the possibility that the $5000 \mathrm{gmU}$ could settle to the bottom of the container into the optimum $\mathrm{H} / \mathrm{U}$ of 25 . From the NUMDEN results, it is known that the uranium density corresponding to $\mathrm{H} / \mathrm{U}=25$ is $.8981 \mathrm{gmU} / \mathrm{cc}$. The volume occupied by $5000 \mathrm{gmU}$ at $\mathrm{H} / \mathrm{U}=25$ can then be calculated as $5000 / .8981=5567.31 \mathrm{~cm}^{3}$. The height of the bottom layer of fissile material is then calculated to preserve this volume for the 5.25 inch diameter container. The resulting height for the bottom layer is 15.7 inches, composed of $97.7 \%$ enriched $\mathrm{UO}_{2} \mathrm{~F}_{2}$ at the optimum $\mathrm{H} / \mathrm{U}$ of 25 . The top layer of material is assumed to be full density water, 8.3 inches high. The contingency and array cases are tabulated in Figure 4.3.1-2.

Aside from changes to the enrichment, the following changes are made in these calculations from Reference 1:

- Cases with $\mathrm{H} / \mathrm{U}$ less than 4 are based on a maximum uranium density of $3.2 \mathrm{gU} / \mathrm{cc}$.

- $100 \mathrm{Kg}$ person is moved back $2^{\prime \prime}$ from the two containers (TACW geometry only).

- Hands are modeled as 6" high, at the top of the container (TACW geometry only).

- Concrete floor is modeled as 12 inches thick (all geometries).

- Concrete walls are modeled as 4 inches thick (all geometries except SFR).

Since the results in Figure 4.3.1-2 indicate that the criticality safety criteria is met for these cases, the conclusion is made that the F-can is safe for storage of $\mathrm{UO}_{2} \mathrm{~F}_{2}+$ Water up to $90 \%$ enrichment. Above $90 \%$ enrichment, the uranium mass must be limited to less than $5000 \mathrm{gmU}$. Storage of individual containers next to (ie. within 1 foot of) concrete walls is permissible, providing the effective thickness of the wall is less than 4 inches. 
Figure 4.3.1-1

Single Fully Reflected 5.25" ID x 24" Tall Cylinder of $97.7 \%$ Enriched $\mathrm{UO}_{2} \mathrm{~F}_{2}+\mathrm{H}_{2} \mathrm{O}$

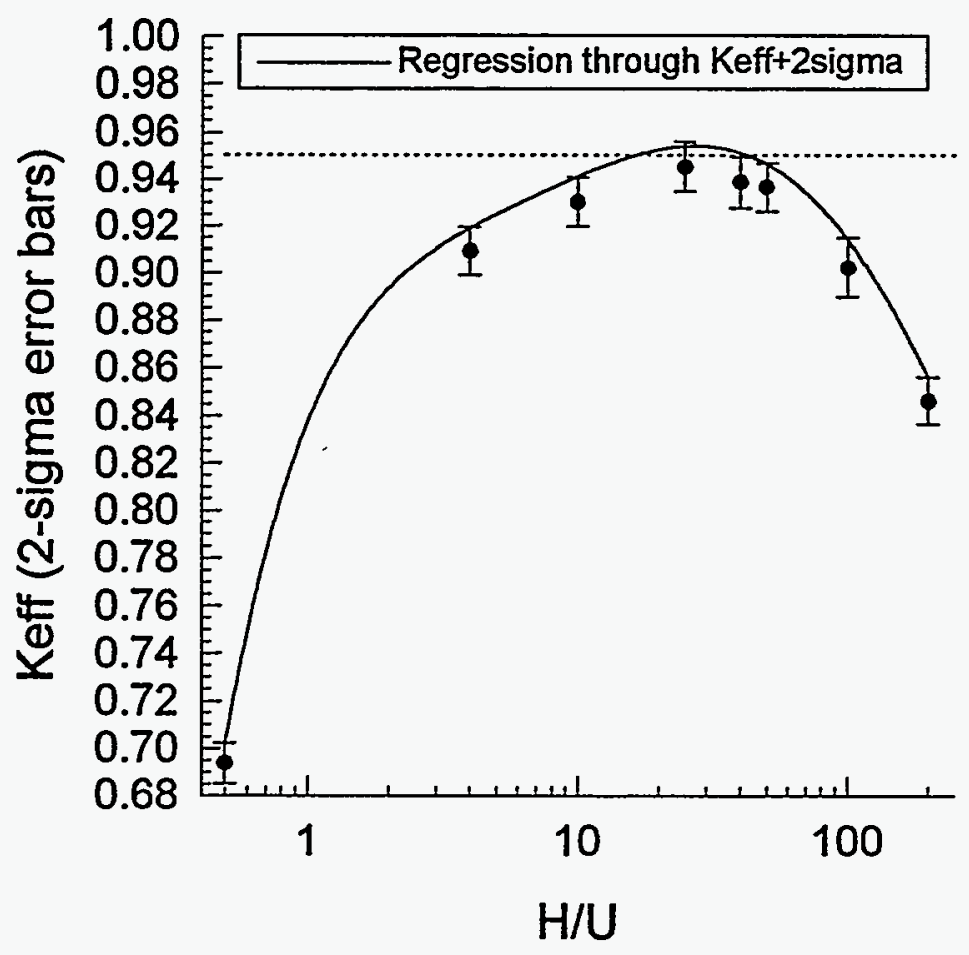

\begin{tabular}{|c|c|c|c|c|c|c|}
\hline \multicolumn{7}{|c|}{$\begin{array}{l}\text { Single } 5.25 \text { in. Diameter Tin Plated Steel Cor } \\
97.7 \% \text { and } 90 \% \text { Enriched } \mathrm{UO}_{2} \mathrm{~F}_{2}+\mathrm{H}_{2} \mathrm{O}\end{array}$} \\
\hline Case & $H / U$ & Keff & $\sigma$ & $2 \sigma$ & Keff $+2 \sigma$ & $\underset{\text { Can }}{\text { GmU In }}$ \\
\hline a977a & 0.5 & 0.69348 & 0.00421 & 0.00842 & 0.70190 & 27244 \\
\hline a977b & 3.99 & 0.90899 & 0.00506 & 0.01012 & 0.91911 & 27244 \\
\hline a977c & 10 & 0.93008 & 0.00521 & 0.01042 & 0.94050 & 15833 \\
\hline a977d & 25 & 0.94514 & 0.00534 & 0.01068 & 0.95582 & 7646 \\
\hline a977h* & 40 & 0.93853 & 0.00551 & 0.01102 & 0.94955 & 5040 \\
\hline a977e & 50 & 0.93641 & 0.00514 & 0.01028 & 0.94669 & 4107 \\
\hline a977f & 100 & 0.90218 & 0.00614 & 0.01228 & 0.91446 & 2133 \\
\hline a977g & 200 & 0.84614 & 0.00486 & 0.00972 & 0.85586 & 1087 \\
\hline a900d & 25 & 0.92857 & 0.00484 & 0.00968 & 0.93825 & 7654 \\
\hline
\end{tabular}

* The a977h case was executed three times with $N P G=300,301$, and 302 because the result was very close to the limit, and because this case sets the mass limit. The worst result (NPG $=301$ ) is tabulated above. 
Figure 4.3.1-2

Contingency and Array Cases for 5.25" ID x 24" Tall Cylinders of 97.7\% Enriched $\mathrm{UO}_{2} \mathrm{~F}_{2}+\mathrm{H}_{2} \mathrm{O}$

\begin{tabular}{|c|c|c|c|c|c|c|}
\hline \multicolumn{7}{|c|}{$\begin{array}{l}5.25 \text { in. Diameter F-can Contingency and Array Cases } \\
\text { for } 97.7 \% \text { Enriched UO2F2+Water }\end{array}$} \\
\hline Case & Geometry & $H / U$ & Keff & $\sigma$ & $2 \sigma$ & Keff $+2 \sigma$ \\
\hline c977h & TACW & 40 & 0.92301 & 0.00521 & 0.01042 & 0.93343 \\
\hline b977h & SCC & 40 & 0.90322 & 0.00549 & 0.01098 & 0.91420 \\
\hline f977h & ACE & 40 & 0.78412 & 0.00303 & 0.00606 & 0.79018 \\
\hline g977h & ACE-F & 40 & 0.93914 & 0.00319 & 0.00638 & 0.94552 \\
\hline h977h & AOSP & 40 & 0.78887 & 0.00317 & 0.00634 & 0.79521 \\
\hline d977d & SFR-SHORT & 25 & 0.90358 & 0.00537 & 0.01074 & 0.91432 \\
\hline e977d & TACW-SHORT & 25 & 0.88913 & 0.00513 & 0.01026 & 0.89939 \\
\hline
\end{tabular}




\subsubsection{Safe Storage of $\mathrm{UF}_{4}+$ Oil in an F-can}

For $\mathrm{UF}_{4}+$ Oil in an F-can, it was necessary to establish safe mass values as a function of enrichment. Single Fully Reflected (SFR) cases were executed for a full range of $\mathrm{H} / \mathrm{U}$ ratios at $60 \%$ enrichment. These results are tabulated and plotted in Figure 4.3.2-1. The results from Figure 4.3.2-1 indicate that the $K_{\text {eff }}+2 \sigma<.95$ criteria is met for this enrichment. Additional SFR cases were executed at $70,80,90$, and $97.7 \%$ enrichment, and various $\mathrm{H} / \mathrm{U}$ ratios, to establish safe mass limits versus enrichment. These cases are tabulated in Figure 4.3.2-2, and form the basis for restricting the allowable $\mathrm{UF}_{4}+$ Oil uranium mass at assays greater than $60 \%$. The mass limit as a function of enrichment is plotted in Figure 4.3.2-3.

The analysis for $\mathrm{UF}_{4}$ in an F-can is completed by executing the remaining contingency and array cases. The SCC, TACW, ACE, ACE-F, and AOSP geometries are analyzed assuming $97.7 \%$ enrichment and an $\mathrm{H} / \mathrm{U}$ of 158.8 , because this material will be permitted by the mass limit, and is the most reactive material identified in the SFR cases. In addition, the SFR-SHORT and TACW-SHORT geometries are analyzed to account for the possibility of a limited mass settling to the bottom of the container into the optimum $\mathrm{H} / \mathrm{U}$ (assumed to be 58.2 based on the $60 \%$ enriched SFR results). The height of the fissile layer was determined based on a mass limit of $1500 \mathrm{gmU}$ at $97.7 \%$ enrichment, and a uranium density at the $\mathrm{H} / \mathrm{U}$ ratio of 58.2 of $.455705 \mathrm{gmU} / \mathrm{cc}$. The volume occupied by $1500 \mathrm{gmU}$ at $\mathrm{H} / \mathrm{U}=58.2$ is calculated as $1500 / .455705=3291.6 \mathrm{~cm}^{3}$. The height of the bottom layer of fissile material is then calculated to preserve this volume for the 5.25 inch diameter container. The resulting height for the bottom layer is 9.3 inches, composed of $97.7 \%$ enriched $\mathrm{UO}_{2} \mathrm{~F}_{2}$ at the optimum $\mathrm{H} / \mathrm{U}$ of 58.2. The top layer of material is assumed to be pure oil, 14.7 inches high. The results from contingency and array cases are tabulated in Figure 4.3.2-4.

Since the results in Figure 4.3.2-4 indicate that the criticality safety criteria is met for the limiting allowable material, the following conclusion is reached. The F-can is safe for storage of $\mathrm{UF}_{4}+$ Oil up to $60 \%$ enrichment. Above $60 \%$ enrichment, the uranium mass must be limited to less than the value defined by the curve in Figure 4.3.2-3. Storage of individual containers next to (ie. within 1 foot of) concrete walls is permissible, providing the effective thickness of the wall is less than 4 inches. 
Figure 4.3.2-1

\section{Single Fully Reflected 5.25" ID x 24" Tall Cylinder of $60 \%$ Enriched UF 4 +Oil}

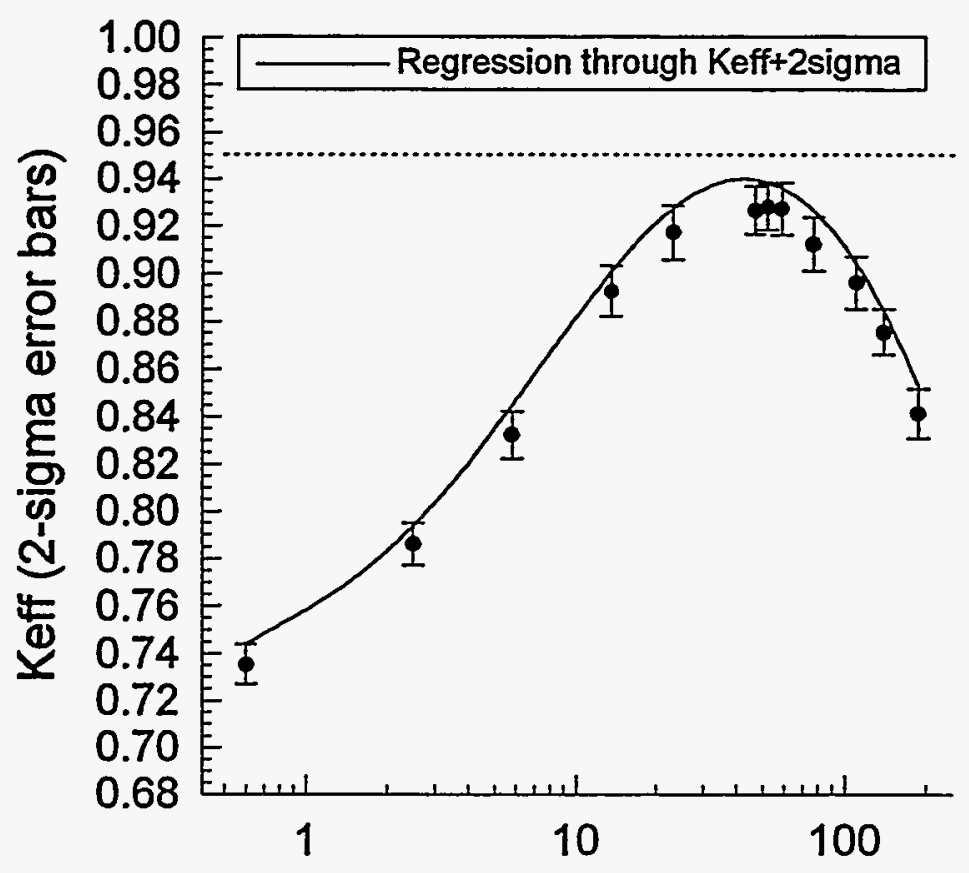

$\mathrm{H} / \mathrm{U}$

\begin{tabular}{|c|c|c|c|c|c|c|}
\hline \multicolumn{7}{|c|}{$\begin{array}{l}\text { Single } 5.25 \text { in. Diameter Tin Plated Steel Container with Full Reflection } \\
\text { for } 60 \% \text { Enriched UF4+Oil }\end{array}$} \\
\hline Case & $H / U$ & Keff & $\sigma$ & $2 \sigma$ & Keff $+2 \sigma$ & $\begin{array}{c}\text { GmU In } \\
\text { Can }\end{array}$ \\
\hline x600r & 0.6 & 0.73534 & 0.00425 & 0.00850 & 0.74384 & 38843 \\
\hline$x 600 p$ & 2.5 & 0.78600 & 0.00445 & 0.00890 & 0.79490 & 30211 \\
\hline$\times 600 \mathrm{n}$ & 5.8 & 0.83220 & 0.00498 & 0.00996 & 0.84216 & 21579 \\
\hline$x 6001$ & 13.5 & 0.89254 & 0.00531 & 0.01062 & 0.90316 & 12948 \\
\hline x600k & 23.1 & 0.91716 & 0.00571 & 0.01142 & 0.92858 & 8632 \\
\hline$x 600 j$ & 46.8 & 0.92647 & 0.00508 & 0.01016 & 0.93663 & 4747 \\
\hline$\times 600 i$ & 52 & 0.92794 & 0.00485 & 0.00970 & 0.93764 & 4316 \\
\hline x600h & 58.5 & 0.92718 & 0.00551 & 0.01102 & 0.93820 & 3884 \\
\hline $\mathrm{x} 600 \mathrm{~g}$ & 76.8 & 0.91234 & 0.00562 & 0.01124 & 0.92358 & 3021 \\
\hline$x 600 f$ & 109.8 & 0.89612 & 0.00551 & 0.01102 & 0.90714 & 2158 \\
\hline$\times 600 \mathrm{~d}$ & 138.7 & 0.87539 & 0.00483 & 0.00966 & 0.88505 & 1726 \\
\hline$x 600 b$ & 186.9 & 0.84131 & 0.00523 & 0.01046 & 0.85177 & 1295 \\
\hline
\end{tabular}


Figure 4.3.2-2

\section{Single Fully Reflected 5.25" ID $\times 24^{\prime \prime}$ Tall Cylinder of $70 \%$ thru $97.7 \%$ Enriched $\mathrm{UF}_{4}+\mathrm{Oil}$}

\begin{tabular}{|c|c|c|c|c|c|c|c|}
\hline \multicolumn{8}{|c|}{$\begin{array}{l}\text { Single } 5.25 \text { in. Diameter Tin Plated Steel Container with Full Reflection } \\
\text { for } 70 \%, 80 ; 90 \text {, and } 97.7 \% \text { Enriched UF4+Oil }\end{array}$} \\
\hline Case & Enrichment & $\mathrm{H} / \mathrm{U}$ & Keff & $\sigma$ & $2 \sigma$ & Keff $+2 \sigma$ & $\begin{array}{c}\text { GmU In } \\
\text { Can }\end{array}$ \\
\hline$\times 700 \mathrm{~d}$ & $70.0 \%$ & 138.6 & 0.90429 & 0.00532 & 0.01064 & 0.91493 & 1726 \\
\hline$\times 700 e$ & $70.0 \%$ & 122.6 & 0.89961 & 0.00522 & 0.01044 & 0.91005 & 1942 \\
\hline$\times 700 f$ & $70.0 \%$ & 109.7 & 0.92624 & 0.00494 & 0.00988 & 0.93612 & 2157 \\
\hline$\times 800 c$ & $80.0 \%$ & 159.1 & 0.90661 & 0.00559 & 0.01118 & 0.91779 & 1510 \\
\hline x800d & $80.0 \%$ & 138.5 & 0.9277 & 0.00586 & 0.01172 & 0.93942 & 1725 \\
\hline x800e & $80.0 \%$ & 122.4 & 0.92638 & 0.00576 & 0.01152 & 0.93790 & 1941 \\
\hline$\times 900 \mathrm{~b}$ & $90.0 \%$ & 186.4 & 0.90336 & 0.00511 & 0.01022 & 0.91358 & 1294 \\
\hline$\times 900 \mathrm{c}$ & $90.0 \%$ & 158.9 & 0.92690 & 0.00579 & 0.01158 & 0.93848 & 1509 \\
\hline$\times 900 \mathrm{~d}$ & $90.0 \%$ & 138.3 & 0.92425 & 0.00552 & 0.01104 & 0.93529 & 1725 \\
\hline$\times 977 b$ & $97.7 \%$ & 186.2 & 0.93018 & 0.00456 & 0.00912 & 0.93930 & 1293 \\
\hline$\times 977 c$ & $97.7 \%$ & 158.8 & 0.93608 & 0.00506 & 0.01012 & 0.94620 & 1509 \\
\hline
\end{tabular}


Figure 4.3.2-3

Safe Mass Limits Versus Enrichment for UF $_{4}+$ Oil in a 5.25" ID $\times 24^{\prime \prime}$ Tall Steel Container

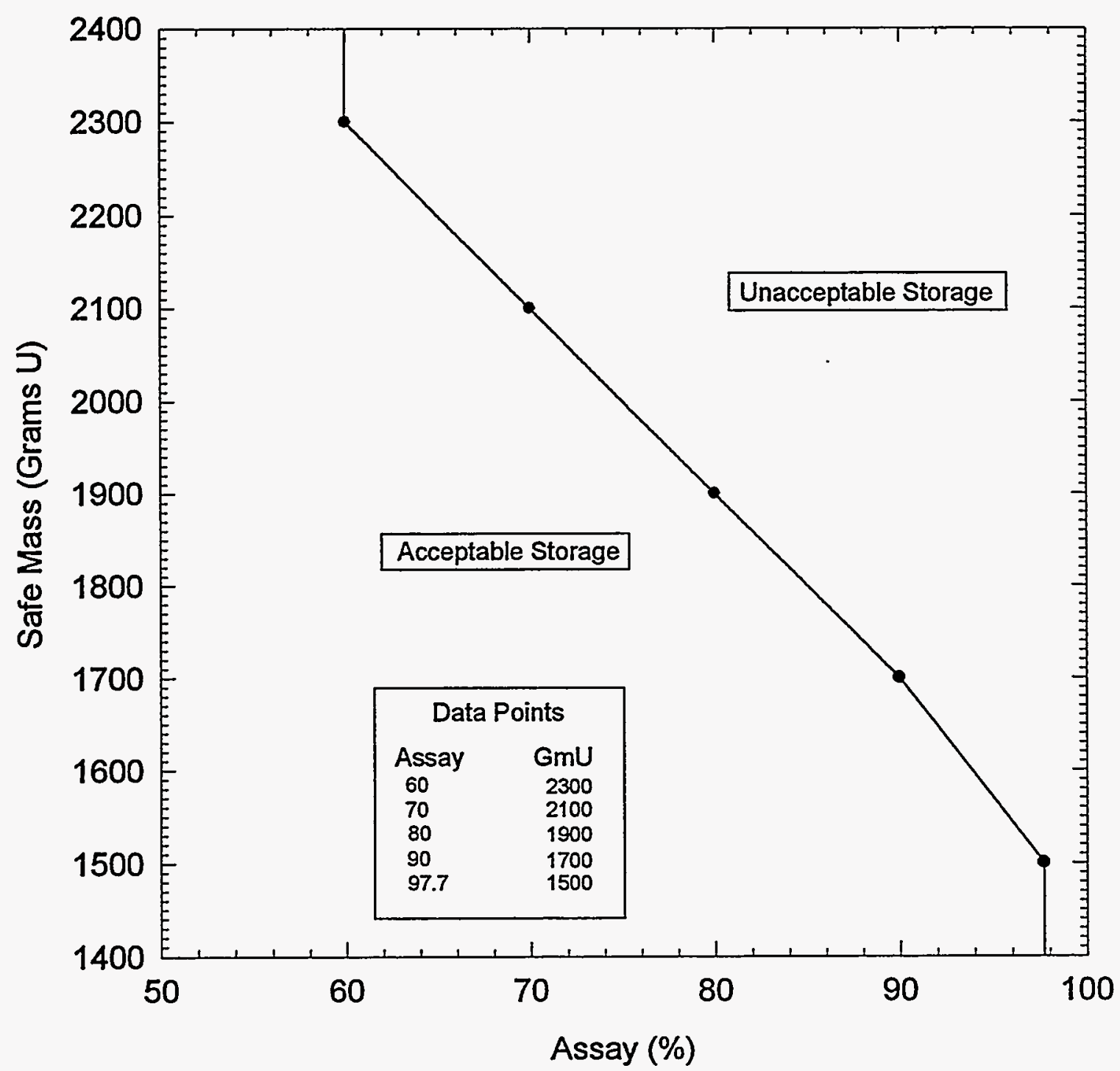


Figure 4.3.2-4

Contingency and Array Cases for 5.25" ID x 24" Tall Cylinders of 97.7\% Enriched $\mathrm{UF}_{4}+$ Oil

\begin{tabular}{|c|c|c|c|c|c|c|}
\hline \multicolumn{7}{|c|}{$\begin{array}{l}5.25 \text { in. Diameter F-can Contingency and Array Cases } \\
\text { for } 97.7 \% \text { Enriched UF4+Oil }\end{array}$} \\
\hline Case & Geometry & $\mathrm{H} / \mathrm{U}$ & Keff & $\sigma$ & $2 \sigma$ & Keff $+2 \sigma$ \\
\hline$z 977 c$ & TACW & 158.8 & 0.93761 & 0.00543 & 0.01086 & 0.94847 \\
\hline y977c & SCC & 158.8 & 0.89655 & 0.00575 & 0.01150 & 0.90805 \\
\hline ac977c & ACE & 158.8 & 0.79286 & 0.00270 & 0.00540 & 0.79826 \\
\hline af977c & ACE-F & 158.8 & 0.94022 & 0.00297 & 0.00594 & 0.94616 \\
\hline ao977c & AOSP & 158.8 & 0.80256 & 0.00327 & 0.00654 & 0.80910 \\
\hline$x \times 977$ & SFR-SHORT & 58.2 & 0.89609 & 0.00635 & 0.01270 & 0.90879 \\
\hline zZ977 & TACW-SHORT & 58.2 & 0.86350 & 0.00566 & 0.01132 & 0.87482 \\
\hline smrc & SMRC & 58.2 & 0.83001 & 0.00582 & 0.01164 & 0.84165 \\
\hline
\end{tabular}




\subsection{25-inch-Diameter by 15-inch-tall Steel Container (Z-can)}

This section presents additional calculations for the "Z-can" container, described in Table 1.0.1. The results presented in Reference 1 demonstrated that the $k_{\text {eff }}+2 \sigma<.95$ criteria was met for most of the $\mathrm{UO}_{2} \mathrm{~F}_{2}+\mathrm{H}_{2} \mathrm{O}$ and $\mathrm{U}_{3} \mathrm{O}_{8}+\mathrm{H}_{2} \mathrm{O}$ cases, but not for the $\mathrm{UF}_{4}+\mathrm{Oil}$ cases. The decision was made not to qualify the $\mathrm{Z}$-can for $\mathrm{UF}_{4}+$ Oil, since there are no plans to store this material in Z-cans in the near future. Only the TACW cases failed to meet the acceptance criteria for the $\mathrm{UO}_{2} \mathrm{~F}_{2}+\mathrm{H}_{2} \mathrm{O}$ and $\mathrm{U}_{3} \mathrm{O}_{8}+\mathrm{H}_{2} \mathrm{O}$ materials. Based on the comparison of the SFR results for $\mathrm{UO}_{2} \mathrm{~F}_{2}+\mathrm{H}_{2} \mathrm{O}$ and $\mathrm{U}_{3} \mathrm{O}_{8}+\mathrm{H}_{2} \mathrm{O}$ (Figures 4.6-1 and 4.6-5 in Reference 1), the conclusion is reached that the $\mathrm{U}_{3} \mathrm{O}_{8}+\mathrm{H}_{2} \mathrm{O}$ case is slightly more reactive than the $\mathrm{UO}_{2} \mathrm{~F}_{2}+\mathrm{H}_{2} \mathrm{O}$ case. Therefore, it was decided to rerun the $\mathrm{U}_{3} \mathrm{O}_{8}+\mathrm{H}_{2} \mathrm{O}$ TACW cases using the revised TACW assumptions described in Section 2.2.5. The range of $\mathrm{H} / \mathrm{U}$ was limited to between 8.7 and 71.2 , consistent with Reference 1 Figure 4.6-7, which clearly indicates that the optimum $\mathrm{H} / \mathrm{U}$ falls somewhere in this range. The results from the additional calculations are tabulated and plotted in Figure 4.4-1. The significant changes from the Reference 1 TACW calculations are:

- $100 \mathrm{Kg}$ person is moved back $2^{\prime \prime}$ from the two containers.

- Hands are modeled as 6 " high, placed at the top of the containers.

The results shown in Figure 4.4-1 indicate that the safety criteria is met for the TACW contingency geometry. Therefore, the Z-can container meets the double contingency requirements, and may be approved for storage of $\mathrm{UO}_{2} \mathrm{~F}_{2}+\mathrm{H}_{2} \mathrm{O}, \mathrm{U}_{3} \mathrm{O}_{8}+\mathrm{H}_{2} \mathrm{O}$, or any other less reactive uranium bearing material, without any restrictions on mass or assay. The container may not be used to store $\mathrm{UF}_{4}+\mathrm{Oil}$, without further analysis. 
Figure 4.4-1

Two 5.25" ID x 15" Tall Cylinders of $\mathrm{U}_{3} \mathrm{O}_{8}+\mathrm{H}_{2} \mathrm{O}$ Next to a Wall

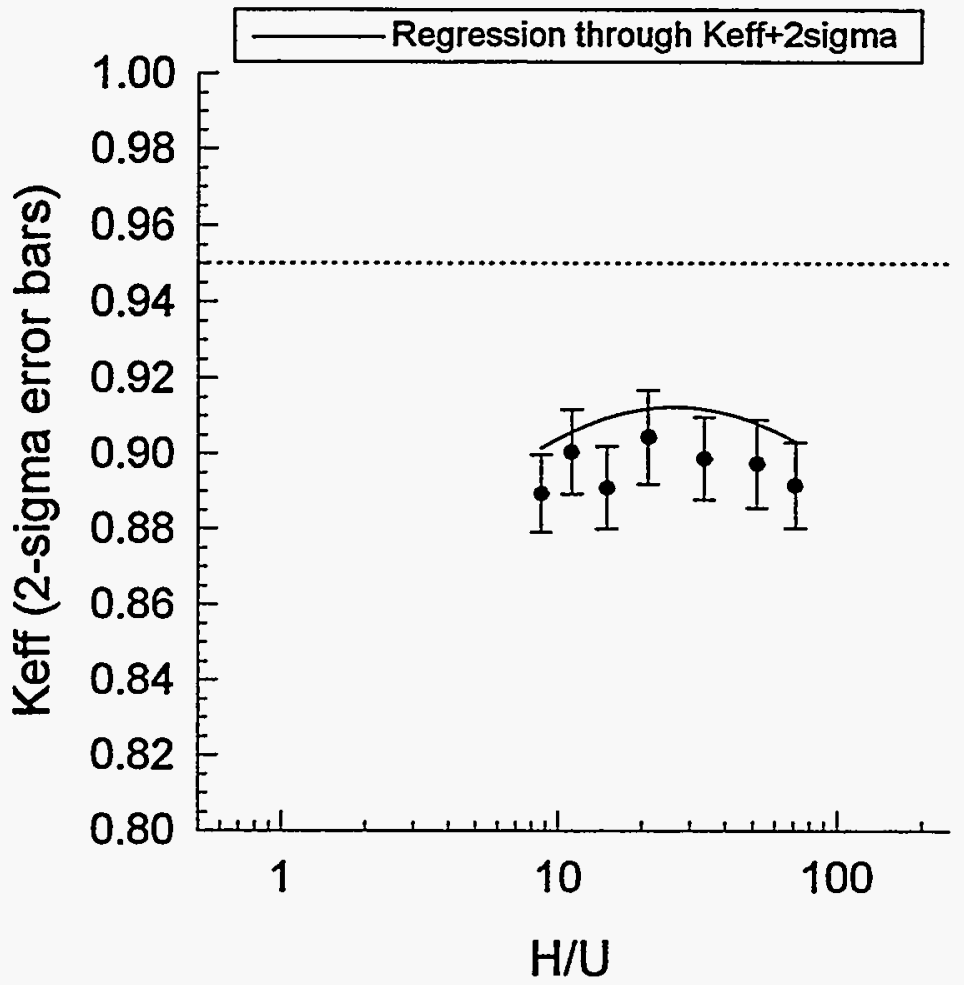

\begin{tabular}{|c|c|c|c|c|c|}
\hline Case & $\mathrm{H} / \mathrm{U}$ & Keff & $\sigma$ & $2 \sigma$ & Keff $+2 \sigma$ \\
\hline $\mathrm{z} 100 \mathrm{a}$ & 71.2 & 0.89133 & 0.00573 & 0.01146 & 0.90279 \\
\hline$z 100 \mathrm{~b}$ & 52.0 & 0.89714 & 0.00592 & 0.01184 & 0.90898 \\
\hline $2100 \mathrm{c}$ & 33.7 & 0.89850 & 0.00553 & 0.01106 & 0.90956 \\
\hline z100d & 21.2 & 0.90421 & 0.00620 & 0.01240 & 0.91661 \\
\hline z100e & 15.0 & 0.89076 & 0.00548 & 0.01096 & 0.90172 \\
\hline$z 100 f$ & 11.2 & 0.90032 & 0.00564 & 0.01128 & 0.91160 \\
\hline $\mathrm{z} 100 \mathrm{~g}$ & 8.7 & 0.88924 & 0.00513 & 0.01026 & 0.89950 \\
\hline
\end{tabular}




\subsection{0-inch-Diameter by 9-inch-tall Polybottle ("CO-4" Polybottle)}

In Reference 1 , it was demonstrated that this container with $\mathrm{U}_{3} \mathrm{O}_{8}+\mathrm{H}_{2} \mathrm{O}$ is bounded by the 5-inch-diameter by 24-inch-high polybottle results for $\mathrm{UO}_{2} \mathrm{~F}_{2}+\mathrm{H}_{2} \mathrm{O}$. As a result, there were no array cases executed for this container, because the array cases for the more limiting container met the criticality safety criteria of $\mathrm{K}_{\text {eff }}+2 \sigma<0.95$. The results documented in this analysis do not change that conclusion. The 24-inch-high polybottle was demonstrated to be safe for $\mathrm{UO}_{2} \mathrm{~F}_{2}+\mathrm{H}_{2} \mathrm{O}$ at any enrichment and $\mathrm{H} / \mathrm{U}$ ratio. The restriction against storage of the 24-inch-high container against concrete walls does not apply to the CO-4 polybottle, because the original Reference 1 TACW results were acceptable (see Figure 4.7-3 in Reference 1). Therefore, the CO-4 Polybottle container meets the double contingency requirements, and may be approved for storage of $\mathrm{UO}_{2} \mathrm{~F}_{2}+\mathrm{H}_{2} \mathrm{O}, \mathrm{U}_{3} \mathrm{O}_{8}+\mathrm{H}_{2} \mathrm{O}$, or any other less reactive uranium bearing material, without any restrictions on mass or assay. The container may not be used to store $\mathrm{UF}_{4}+\mathrm{Oil}_{\text {, }}$ without further analysis.

\subsection{Array Position Relative to Concrete Wall}

In Reference 1, supplemental standard array (ACE) cases were run to examine the effect of positioning the array closer to the 12-inch concrete wall. The limiting array cases in Reference 1 with $100 \%$ enriched material were re-executed with the array being only one foot from the wall instead of two (See Reference 1, Figure 4.8-5). The results showed a maximum increase in the K-eff of the unmoderated array of only .0084 . For a fully moderated array (ACE-F geometry), the K-effective would not be expected to change if the array is moved to within 1 foot of the wall, because the water would act to thermalize all neutrons before they could get to the wall. The effect of neutron reflection from the concrete wall would be effectively negated by the presence of water between the array and the wall. The limiting dry array case identified in this analysis is the AOSP contingency case for the 5 -inch diameter by 24 -inch high polybottle with $80 \%$ enriched $\mathrm{UF}_{4}+$ Oil. The resulting maximum K-effective $+2 \sigma$ for this case was .83667 . Adding a conservative $\delta k$ of .01 to account for placing the array one foot from the concrete wall, gives a $\mathrm{K}$ effective $+2 \sigma$ of .84667 , which is still well within the acceptance criteria. Based on this result, the conclusion is reached that all of the standard arrays analyzed in Reference 1 and in this analysis are safe when placed at least one foot away from a concrete wall. 


\section{$\underline{5.0}$ References}

1.0 POEF-SH-30, Maria S. LeTellier, et al., "Nuclear Criticality Safety Calculational Analysis for Small-Diameter Containers," Battelle Memorial Institute, November 1995.

2.0 Validation of the CSAS25 Calculation Sequence in SCALE-4.2 and the 27 Energy Group ENDF/B-IV Cross Sections on the Battelle Process Safety and Risk Management IBM RS/6000 Workstation.

3.0 Conditional Validation of CSAS25 on Battelle Process Safety and Risk Management RS/6000 (Battelle 1994).

4.0 Configuration Control Plan for Process Safety and Risk Management Nuclear Safety Software \& Hardware Systems (RS/6000) (Battelle, August 1994).

5.0 Letter from R. W. Tayloe to D. M. D'Aquila, "Standard Reflection Conditions for Analysis of Containers at the Portsmouth Plant", June 2, 1995.

6.0 K/ETO-143, Barber E. J. "Reaction of Uranium Hexafluoride with Hydrocarbon Oil," Enrichment Technical Support Department, August, 1994.

7.0 POEF-T-3545, Tayloe, R. W. "Calculating Atomic Number Densities for Uranium Compounds," Battelle Memorial Institute, January 1993.

8.0 GAT-225, Revision 4, "Nuclear Criticality Safety Guide for the Portsmouth Gaseous Diffusion Plant."

9.0 SCALE 4.1 Manual, March 1992.

10.0 General Electric Chart of the Nuclides, Fourteenth Edition, April 1988.

11.0 Perry, R. H. and Cecil H. Chilton, "Chemical Engineers' Handbook, 5th Ed.", McGraw-Hill Book Co. 


\subsection{Appendix}

Note: All sample decks are for F-cans (see Figures 4.3.2-2 and 4.2.2.4)

\subsection{Sample Input deck for SFR geometry (deck x977c)}

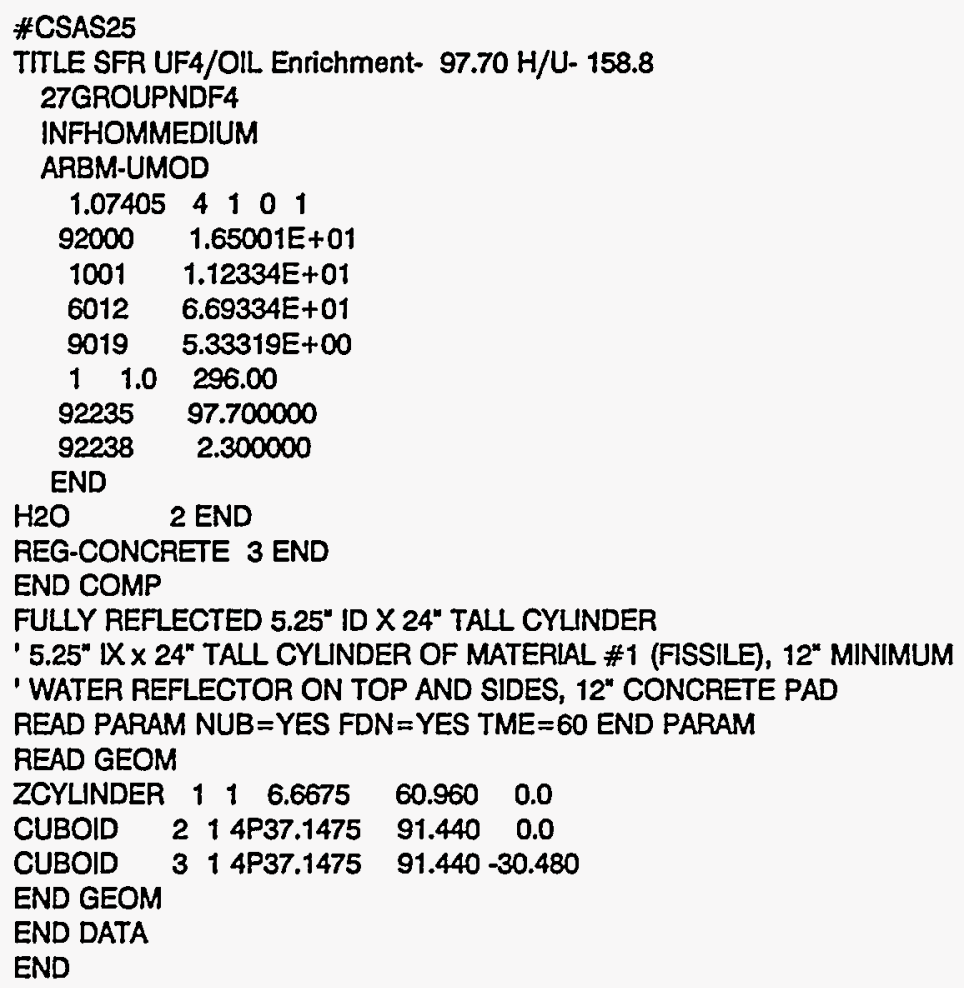




\subsection{Sample Input deck for SCC geometry (deck y977c)}

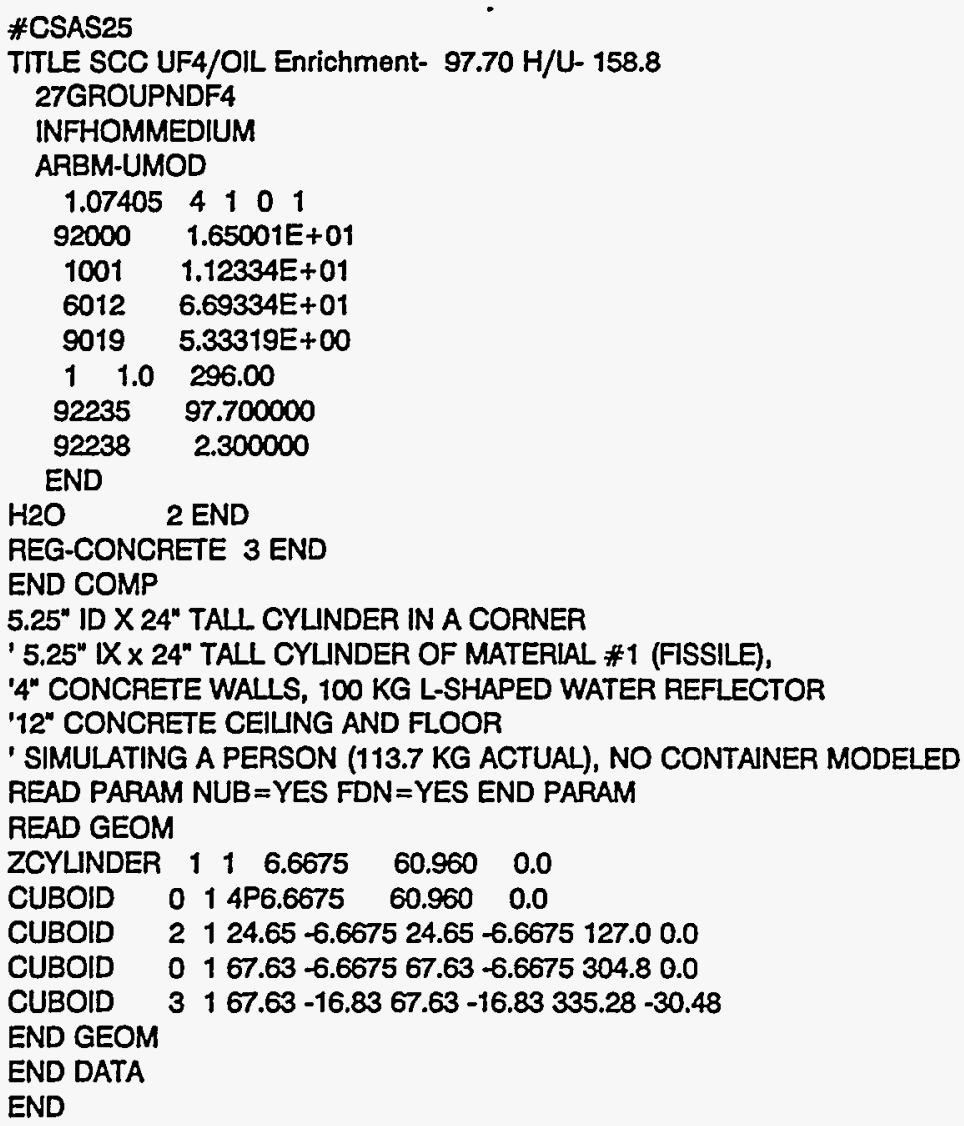




\subsection{Sample Input deck for TACW geometry (deck z977c)}

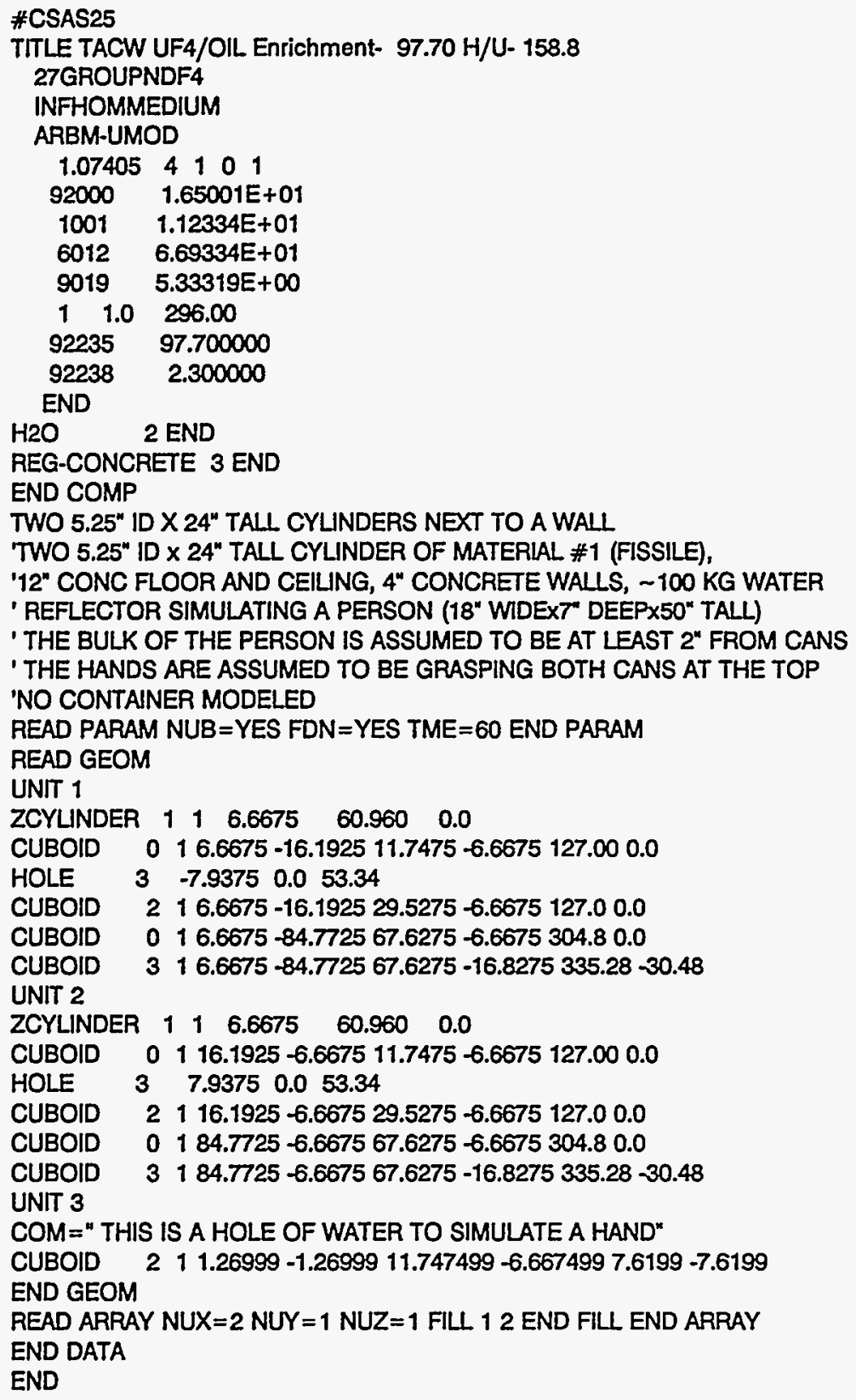




\subsection{Sample Input deck for ACE geometry (deck ac977c)}

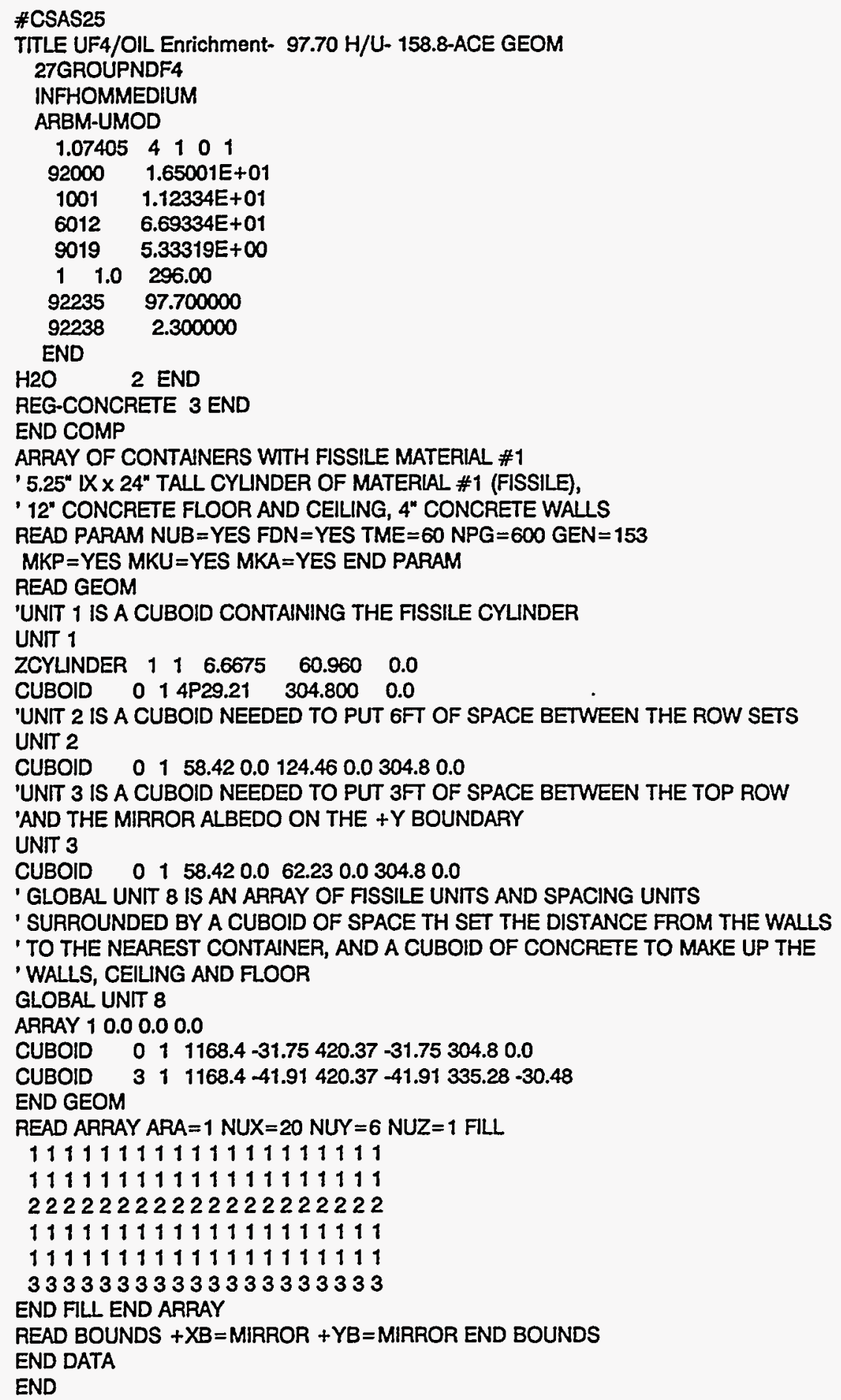




\subsection{Sample Input deck for ACE-F geometry (deck af977c)}

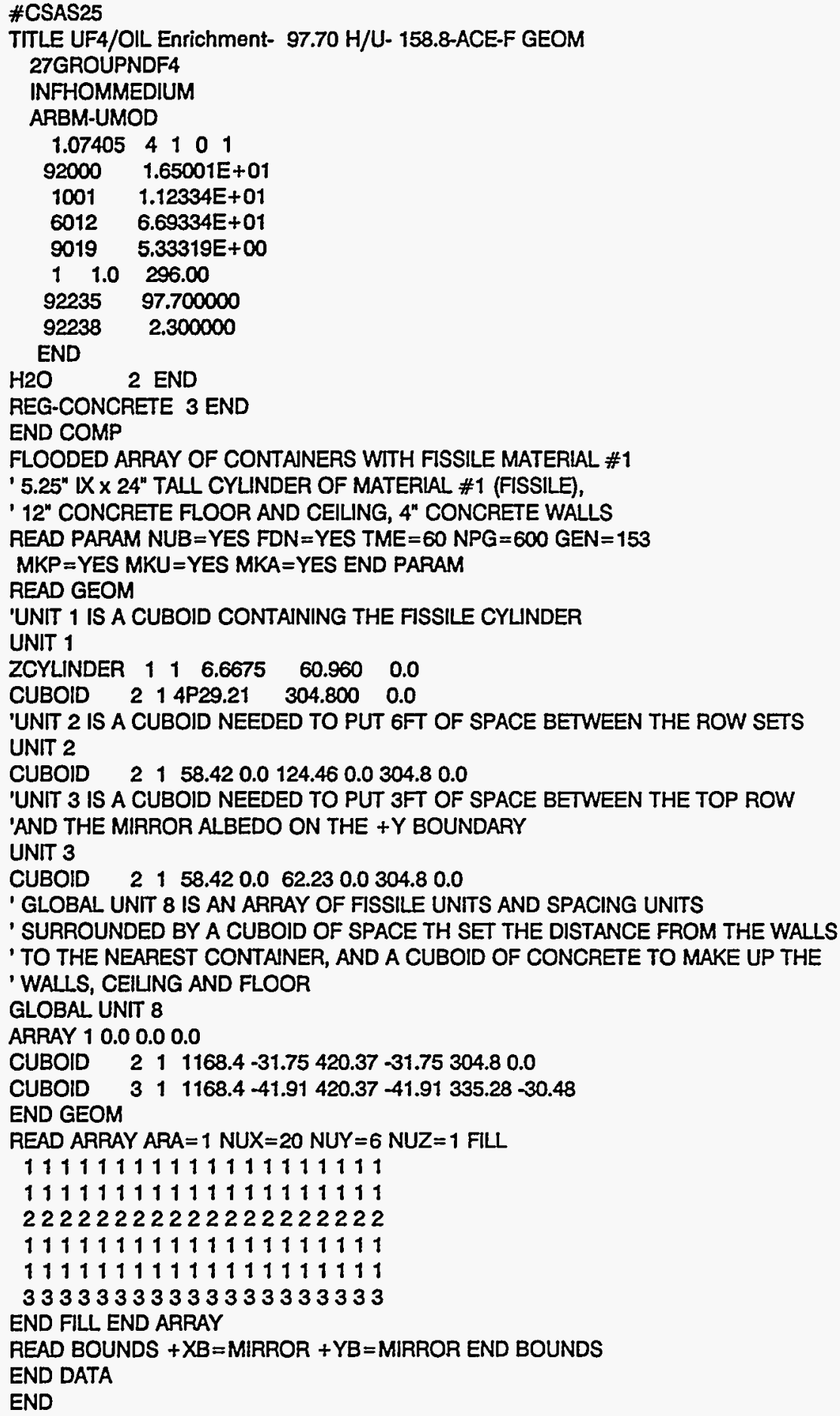




\subsection{Sample Input deck for AOSP geometry (deck a0977c)}

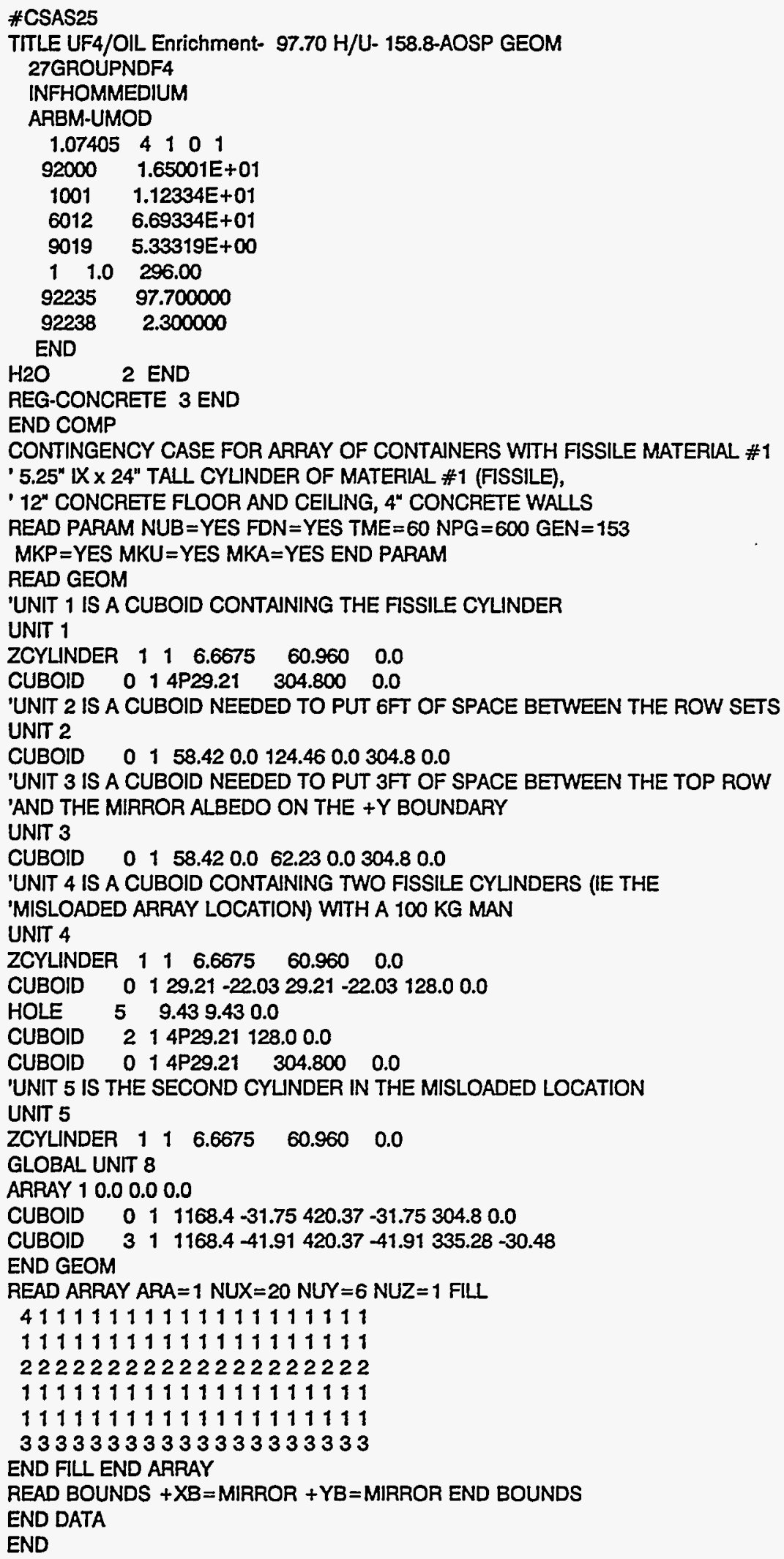




\subsection{Sample Input deck for SFR-SHORT geometry (deck xx977)}

\#CSAS25

TITLE SFR UF4/OIL Enrichment- $97.70 \mathrm{H} / \mathrm{U}-58.2$ - SHORT

27GROUPNDF4

INFHOMMEDIUM

ARBM-UMOD

$1.3947 \quad 4 \quad 1001$

$92000 \quad 3.26741 E+01$

$1001 \quad 8.15772 \mathrm{E}+\infty 0$

$6012 \quad 4.86072 E+01$

$9019 \quad 1.05610 E+01$

$\begin{array}{lll}1 & 1.0 & 296.00\end{array}$

$92235 \quad 97.700000$

$92238 \quad 2.300000$

END

$\mathrm{H} 2 \mathrm{O} 2 \mathrm{END}$

REG-CONCRETE 3 END

ARBM-OIL

0.870020010

$1001 \quad 2.0$

$6012 \quad 1.0$

$\begin{array}{lll}4 & 1.0 & 296.00\end{array}$

END

END COMP

FULLYY REFLECTED 5.25" ID X 24" TALL CYLINDER

'CYLINDER CONTAINS A SETTLED MIXTURE OF UF4 AND OIL

WITH THE FISSILE MATERIAL OCCUPYING THE BOTTOM $9.3^{*}$

'AND OIL FILLING UP THE REST OF THE CAN. THE TOTAL MASS OF U IN 'THE SETTLED MATERIAL IS 1500 GM-U.

' 5.25" IX $\times 24^{\prime \prime}$ TALL CYLINDER OF MATERIAL \#1 (FISSILE), 12" MINIMUM

' WATER REFLECTOR ON TOP AND SIDES, 12 " CONCRETE PAD

READ PARAM NUB $=Y E S$ FDN $=Y E S T M E=60$ END PARAM

READ GEOM

$\begin{array}{llllll}\text { ZCYLINDER } & 1 & 1 & 6.6675 & 23.600 & 0.0\end{array}$

ZCYLINDER $\quad 4 \quad 1 \quad 6.6675 \quad 60.960 \quad 0.0$

$\begin{array}{llllll}\text { CUBOID } \quad 2 & 1 & \text { 4P37.1475 } & 91.440 & 0.0\end{array}$

CUBOID $\quad 3 \quad 14$ P $37.1475 \quad 91.440-30.480$

END GEOM

END DATA

END 


\subsection{Sample Input deck for TACW-SHORT geometry (deck 2z977)}

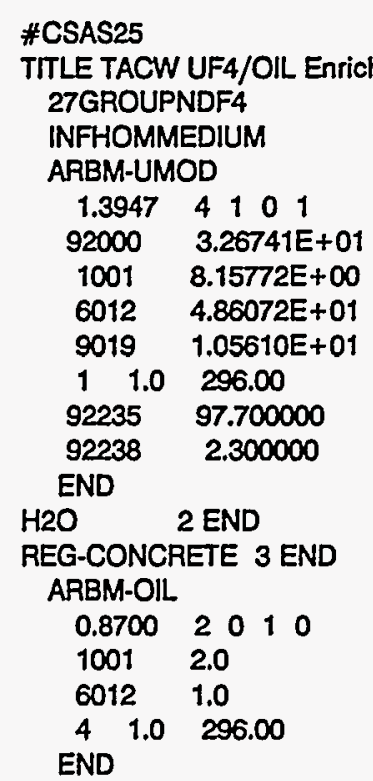

END COMP

TWO 5.25" ID X 24" TALL CYLINDERS NEXT TO A WALL

'BOTH CYLINDERS CONTANN A SETTLED MIXTURE OF UF4 AND OIL

'WITH THE FISSILE MATERIAL OCCUPYING THE BOTTOM 9.3"

'AND OIL FILLING UP THE REST OF THE CAN. THE TOTAL MASS OF U IN 'THE SETTLED MATERIAL IS $1500 \mathrm{GM}$-U.

' 12 " CONC FLOOR AND CEILING, 4" CONCRETE WALLS, - $100 \mathrm{KG}$ WATER

'REFLECTOR SIMULATING A PERSON (18" WIDEX7" DEEP $550^{\prime \prime}$ TALL)

' THE BULK OF THE PERSON IS ASSUMED TO BE AT LEAST 2" FROM CANS

' THE HANDS ARE ASSUMED TO BE GRASPING BOTH CANS AT THE TOP

'NO CONTAINER MODELED

READ PARAM NUB $=$ YES FDN $=$ YES $T M E=60$ END PARAM

READ GEOM

UNIT 1

$\begin{array}{llllll}\text { ZCYLINDER } & 1 & 1 & 6.6675 & 23.600 & 0.0\end{array}$

$\begin{array}{llllll}\text { ZCYLINDER } & 4 & 1 & 6.6675 & 60.960 & 0.0\end{array}$

CUBOID 0 1 $6.6675-16.192511 .7475-6.6575127 .000 .0$

$\begin{array}{lllll}\text { HOLE } & 3 & \mathbf{- 7 . 9 3 7 5} & 0.0 & 53.34\end{array}$

CUBOID $\quad 2 \quad 16.6675-16.192529 .5275-6.6675127 .00 .0$

CUBOID $\quad 0 \quad 16.6675-84.7725 \quad 67.6275-6.6675304 .80 .0$

CUBOID $\quad 316.6675-84.772567 .6275-16.8275335 .28-30.48$

UNIT 2

$\begin{array}{llllll}\text { ZCYLINDER } & 1 & 1 & 6.6675 & 23.600 & 0.0\end{array}$

$\begin{array}{llllll}\text { ZCYLINDER } & 4 & 1 & 6.6675 & 60.960 & 0.0\end{array}$

CUBOID 0 1 $16.1925-6.667511 .7475-6.6675127 .000 .0$

$\begin{array}{lllll}\text { HOLE } & 3 & 7.9375 & 0.0 & 53.34\end{array}$

CUBOID $2116.1925-6.667529 .5275-6.6675127 .00 .0$

CUBOID $\quad 0 \quad 184.7725-6.667567 .6275-6.6675304 .80 .0$

CUBOID $\quad 3 \quad 184.7725-6.667567 .6275-16.8275335 .28-30.48$

UNIT 3

COM $=$ " THIS IS A HOLE OF WATER TO SIMULATE A HAND"

CUBOID 2 1 1.26999-1.26999 11.747499-6.667499 7.6199-7.6199

END GEOM

READ ARRAY NUX=2 NUY=1 NUZ=1 FILL 12 END FILL END ARRAY

END DATA

END 


\subsection{Sample Input deck for SMRC geometry (deck smrc)}

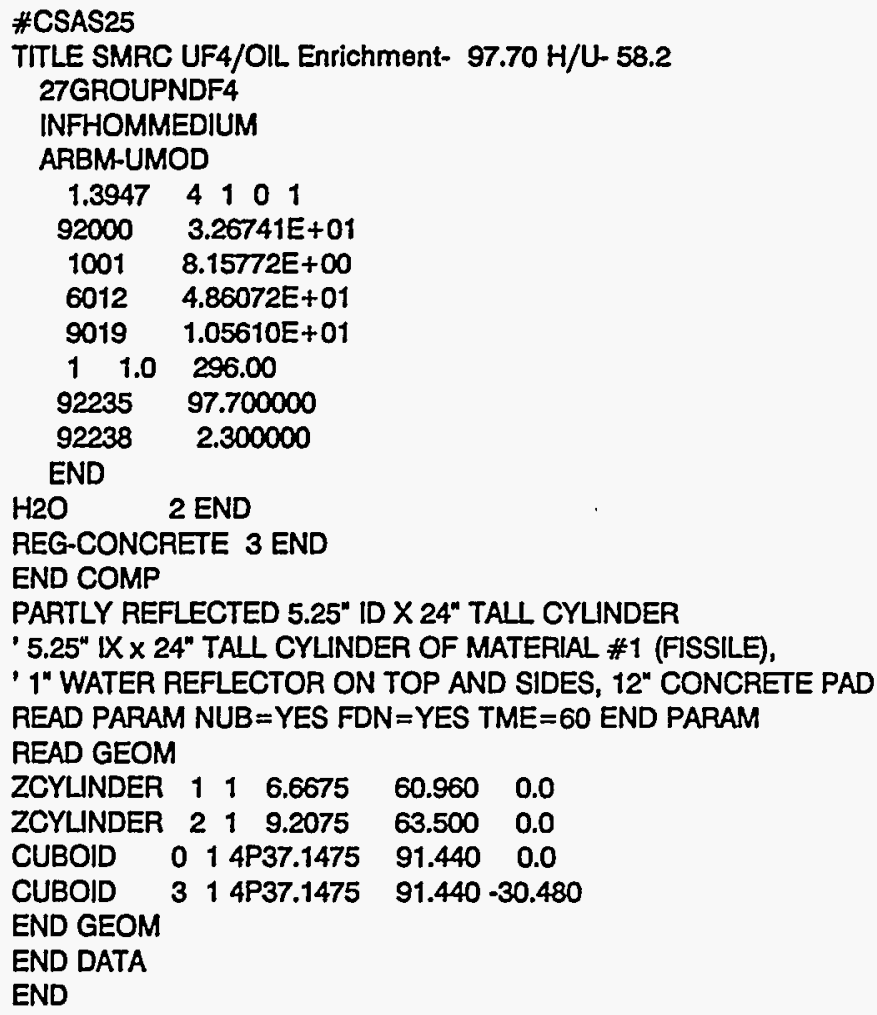

